\title{
Self-Assembled Monolayers of Oligophenylenecarboxylic Acids on Silver Formed at the Liquid-Solid Interface
}

\author{
Hannah Aitchison, ${ }^{\mathrm{a}}$ Hao Lu, ${ }^{\mathrm{b} \ddagger}$ Simon W.L. Hogan, ${ }^{\mathrm{a}}$ Herbert Früchtl, ${ }^{\mathrm{a}}$ Izabela Cebula, ${ }^{\mathrm{a} \dagger}$ Michael \\ Zharnikov ${ }^{\mathrm{b}}$ and Manfred Buck ${ }^{\mathrm{a} *}$ \\ ${ }^{a}$ EaStCHEM School of Chemistry, University of St Andrews, North Haugh, St Andrews KY16 9ST \\ ${ }^{\mathrm{b}}$ Angewandte Physikalische Chemie, Universität Heidelberg, Im Neuenheimer Feld 253, 69120 Heidelberg, \\ Germany \\ KEYWORDS Carboxylic acids, metal-organic coordination bonding, molecular self-assembly, liquid-solid \\ interface, underpotential deposition
}

\begin{abstract}
A series of para-oligophenylene mono- and dicarboxylic acids $\left(\mathrm{R}-\left(\mathrm{C}_{6} \mathrm{H}_{4}\right)_{\mathrm{n}} \mathrm{COOH}, \mathrm{n}=1-3, \mathrm{R}=\mathrm{H}, \mathrm{COOH}\right)$ was studied. Adsorbed on $\mathrm{Au}(111) /$ mica modified by an underpotential deposited bilayer of Ag, the self-assembled monolayers (SAMs) were analysed by near edge X-ray absorption fine structure spectroscopy, X-ray photoelectron spectroscopy and scanning tunneling microscopy. In all cases SAMs are formed with molecules adopting an upright orientation and anchored to the substrate by a carboxylate. Except benzoic acid, all SAMs could be imaged at molecular resolution, which revealed highly crystalline layers with a dense molecular packing. The structures of the SAMs are described by a rectangular $(5 \times \sqrt{3})$ unit cell for the prevailing phase of the monocarboxylic acids and an oblique $\left(\sqrt{ }_{93} \times \sqrt{133}_{13}\right)$ unit cell for the dicarboxylic acids, thus, evidencing a pronounced influence of the second $\mathrm{COOH}$ moiety on the SAM structure. Density functional theory calculations suggest that hydrogen bonding between the SAM terminating $\mathrm{COOH}$ moieties accounts for the difference. Contrasting other classes of SAMs, the systems studied here are determined by intermolecular interactions whereas molecule-substrate interactions play a secondary role. Thus, eliminating problems arising from the mismatch between the molecular and substrate lattices, coordinatively bonded carboxylic acids on silver should provide considerable flexibility in the design of SAM structures.
\end{abstract}




\section{INTRODUCTION}

As essential constituents of supramolecular structures such as metal-organic frameworks (MOFs) and hydrogen bonded networks, aromatic carboxylic acids are widely exploited in self-assembly processes both in the solution phase and at interfaces. On metal or graphite surfaces the focus has been on the formation of two dimensional molecular patterns of flat lying molecules through either hydrogen bonding or metal-organic coordination. ${ }^{1-12}$ Investigations comprise both the ultrahigh vacuum (UHV) environment and the liquid/solid interface, the latter also including the electrochemical interface. ${ }^{13-17}$ Compared to these activities only a few studies have focused on the formation of self-assembled monolayers (SAMs) where, analogous to the extensively studied thiols and silanes ${ }^{18-19}$, molecules adopt an upright configuration with the carboxylate moiety acting as head group to anchor the molecule via coordination bonding. Preparation from solution might be preferred in this case as in UHV an incomplete layer or a layer with a mixture of flat lying and upright standing molecules is usually obtained, ${ }^{20-23}$ even though examples of extended islands of full layers of upright standing molecules have been reported for 1,2,4-benzenetricarboxylic acid on $\mathrm{Cu}(100)^{24}$, and terephthalic acid on rutile $e^{25-26}$ and $\mathrm{Cu}(100){ }^{27-28}$ Notably, for terephthalic acid on $\mathrm{Cu}$ the upright configuration was found for the second layer.

The solution based studies have been performed almost exclusively on fatty acids (for references see reviews by Ulman $^{29}$ and Jadhav ${ }^{30}$ ) with the exception of terephthalic acid, ${ }^{31}$ alkoxy derivatised biphenyl-, naphthyl- and benzenecarboxylic acid, and terphenylcarboxylic acid. ${ }^{32-34}$ To this small set of spectroscopic studies, benzene-1,3dicarboxylic acid (isophthalic acid, IPA), benzene-1,3,5tricarboxylic acid (trimesic acid, TMA) and biphenyl3,4',5-tricarboxylic acid (BPTCA) have recently been

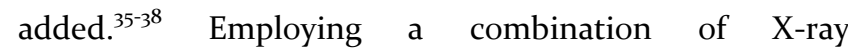
spectroscopies and scanning tunneling microscopy at molecular resolution, these studies revealed that ordered layers are formed on $\mathrm{Cu}$ and $\mathrm{Ag}$ prepared as underpotential deposited layers on Au. Apart from providing insights into the very initial stages of thin film

\footnotetext{
* There are varying interpretations of the term self-assembled monolayer. As used in the paper it refers to monomolecular layers where molecules are densely packed and adsorbed in an upright geometry.
}

growth of MOFs, ${ }^{36}$ the combination of spectroscopy and microscopy revealed striking differences between the two metals. The weaker coordination bond between the carboxylate and $\mathrm{Ag}$ compared to $\mathrm{Cu}$ results in a very different balance between molecule-substrate and intermolecular interactions. ${ }^{37-38}$ This, in particular, is pinpointed by pronouncedly different adsorption geometries of TMA and BPTCA on Ag where a monopodal configuration is realised compared to $\mathrm{Cu}$ which yields a bipodal configuration.

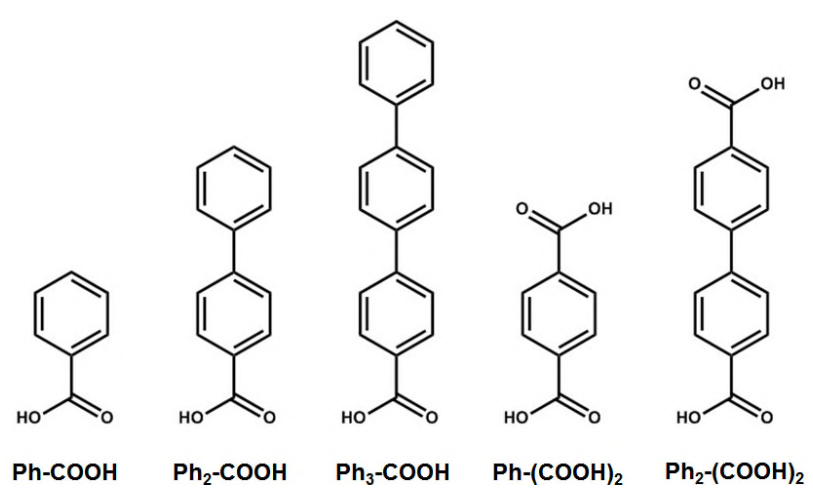

Scheme 1. The series of molecules under investigation in this work. From left to right: benzoic acid, biphenyl-4-carboxylic acid, terphenyl-4-carboxylic acid, terephthalic acid, and biphenyl-4,4'-dicarboxylic acid.

Envisioning that assembly of carboxylic acids on $\mathrm{Ag}$ provide a flexible route to structurally well-defined SAMs, the homologue series of oligophenylene mono- and dicarboxylic acids shown in Scheme 1 was investigated in order to systematically study the influence of the number of aromatic rings on both the conditions of film formation and the resulting structure of the SAMs. From the unexpected differences observed for TMA and BPTCA $^{38}$ it is a priori not clear how the SAM structures of all the molecules are correlated and how much the second carboxylic acid group, which would be very differently orientated compared to the systems studied so far, affects the SAM structure.

With the need of using a combination of microscopy and spectroscopy highlighted by the study of $\mathrm{TMA}^{37}$ and BPTCA $^{38}$, here we report the results of scanning tunneling microscopy (STM), X-ray photoelectron spectroscopy (XPS) and near-edge X-ray adsorption fine structure (NEXAFS) spectroscopy in combination with DFT calculations to assist the interpretation of the data. For the studies Au/mica substrates were used, which have been modified by an underpotential deposited (UPD) bilayer of Ag..$^{39-40}$ Since $\mathrm{Ag}$ and Au have essentially the same lattice constants, the UPD layer is less reactive 
compared to evaporated films and, furthermore, protected by anions, this provides a convenient access to a high quality (111) oriented surface of Ag. ${ }^{35,41-42}$

\section{EXPERIMENTAL METHODS}

Sample preparation. Benzoic acid ( $\geq 99.5 \%$, SigmaAldrich), terephthalic acid (98\%, Sigma-Aldrich), terphenyl-4-carboxylic acid (97\% Sigma-Aldrich), $\mathrm{AgNO}_{3}$ (99.9999\%, Sigma-Aldrich) and ethanol (AnalaR Normapur) were used as purchased. Biphenyl-4carboxylic acid (95\%, Sigma-Aldrich) and biphenyl-4,4'dicarboxylic acid (97\%, Sigma-Aldrich), were recrystallized from ethanol prior to use. Au substrates (300 nm epitaxial Au(111) layer on mica wafer, Georg Albert PVD, Heidelberg, Germany) were annealed using a natural gas flame before underpotential deposition of a pseudomorphic (1×1) Ag bilayer was carried out. Au/mica was immersed in $10 \mathrm{mM} \mathrm{AgNO}_{3}$ in $100 \mathrm{mM} \mathrm{HNO}_{3}$ (aq) and a potential of $10 \mathrm{mV}$ (vs. $\mathrm{Ag} / \mathrm{Ag}^{+}$) was applied to the substrate for 2 minutes. This yields full coverage of a stable bilayer of silver atoms covered with adsorbate layer of nitrate ions. ${ }^{40,43-45}$

For SAM formation, the Ag modified substrate was immersed in a solution of the surfactant molecule. Molecules adsorb by displacing the nitrate ions as evidenced by the XPS $\mathrm{N}_{1} \mathrm{~S}$ signal. A $0.5 \mathrm{mM}$ in a 1:1 $\mathrm{H}_{2} \mathrm{O}$ : EtOH solvent mixture was used for all molecules in the series with the exception of a saturated aqueous solution in the case of $\mathrm{Ph}_{2}-(\mathrm{COOH})_{1} . \mathrm{Ph}_{2}-(\mathrm{COOH})_{1}$ monolayers have also been prepared from 1:1 $\mathrm{H}_{2} \mathrm{O}$ : EtOH solutions but the layer quality was improved when prepared from aqueous solution. Specific preparation methods for each SAM are as follows: 10 minutes at room temperature (RT) for $\mathrm{Ph}-\mathrm{COOH}$ and $\mathrm{Ph}-(\mathrm{COOH})_{2} ; 5$ minutes at $65{ }^{\circ} \mathrm{C}$ for $\mathrm{Ph}_{2}-\mathrm{COOH}$ and $\sim 18$ hours at $65^{\circ} \mathrm{C}$ for $\mathrm{Ph}_{3}-\mathrm{COOH}$ and $\mathrm{Ph}_{2}-(\mathrm{COOH})_{2}$. After the immersion, the substrate was thoroughly rinsed with RT EtOH before being dried under a flow of $\mathrm{N}_{2}(\mathrm{~g})$. Higher temperatures were required for the larger molecules in the series since they are poorly soluble in water and water/ethanol mixtures.

Before STM analysis, the dicarboxylic acid SAMs were rinsed briefly $(\sim 3$ seconds) with an ethanolic solution of $\mathrm{NaOH}$ (1 mM, Sigma Aldrich, 99.2\%) and dried under a flow of $\mathrm{N}_{2}(\mathrm{~g})$. This greatly improved resolution, most likely by rinsing away any physisorbed molecules on the monolayer surface. The structures of SAMs prepared with and without this alkali rinsing were carefully compared using STM, XPS and NEXAFS spectroscopy to verify that they were not affected by the $\mathrm{NaOH}$.
Characterization. Each sample was characterized at RT by STM and synchrotron based XPS and NEXAFS spectroscopy.

STM imaging was carried out using a Molecular Imaging PicoSPM system in ambient atmosphere. Tips were mechanically cut from Pt/Ir 80:20 wire (Advent Research Materials Ltd, $0.25 \mathrm{~mm}$ diameter). Typical tunneling parameters of $0.002-0.070 \mathrm{nA}$ and a tip bias of $\pm 0.20-$ o.6o V were used.

XPS and NEXAFS measurements were carried out at the bending magnet HE-SGM beamline of the synchrotron storage ring BESSY II in Berlin, Germany. XP spectra were collected in normal emission geometry using a Scienta $\mathrm{R}_{3000}$ spectrometer. The energy resolution was $\sim 0.3 \mathrm{eV}$ at an excitation energy of $350 \mathrm{eV}$ and somewhat lower at higher excitation energy. The binding energy (BE) scale was referenced to the $\mathrm{Au} 4 \mathrm{f}_{7 / 2}$ peak at a $\mathrm{BE}$ of $84.0 \mathrm{eV} .^{46}$ Spectra were fitted by symmetric Voigt functions and a linear background using Casa-XPS.

The NEXAFS spectroscopy measurements were made using a partial electron yield detector. The spectra were collected at both carbon and oxygen K-edges with retarding voltages of $150 \mathrm{~V}$ and $350 \mathrm{~V}$, respectively. Linear polarized X-ray light with a polarization factor of $\sim 91 \%$ was used. The energy resolution was $\sim 0.30 \mathrm{eV}$ for the $\mathrm{C} \mathrm{K}$ edge and somewhat lower for the $\mathrm{O} \mathrm{K}$-edge. The incident angle of the X-ray light was varied from $90^{\circ}$ (E-vector in the surface plane) to $20^{\circ}$ (E-vector nearly normal to the surface plane) in steps of $10-20^{\circ}$ to monitor orientational order of the aromatic carboxylic acid molecules in the SAMs. This approach is based on the linear dichroism in $\mathrm{X}$-ray absorption, i.e. the strong dependence of the crosssection of the resonant photoexcitation process on the orientation of the electric field vector of the linearly polarized light with respect to the molecular orbital of interest. $^{47}$

The raw NEXAFS spectra were normalized to the incident photon flux by division by a spectrum of clean, freshly sputtered gold sample. Afterwards, the spectra were reduced to standard form by subtracting a linear pre-edge background and normalizing to the unity jump edge in the far post-edge range. The energy scale of the C K-edge spectra was referenced to the most intensive $\pi^{*}$ resonance of highly orientated pyrolytic graphite at $285.38 \mathrm{eV} .{ }^{48}$ The relative shift of the $\mathrm{O}$ K-edge range was estimated using reference XPS measurements.

DFT calculations. Calculations of $\mathrm{Ph}_{2}-\mathrm{COOH}$ and $\mathrm{Ph}_{2}-$ $(\mathrm{COOH})_{2}$ SAMs were carried out using the VASP program, ${ }^{49-51}$ using the PBE functional ${ }^{12-53}$ with Grimme's 
D3 VdW correction ${ }^{54}$ and a plane wave basis set with a $500 \mathrm{eV}$ energy cut off. The metal slab consisted of three Au layers and two Ag layers with $23 \AA$ for the molecular layer and vacuum gap above it. The molecules and the uppermost Ag layer were allowed to relax. The bottom two Au layers were frozen at the bulk Au geometry and the geometry of the other metal layers was optimized then also frozen. Dipole corrections were applied in the direction orthogonal to the surface..$^{5-56}$

\section{RESULTS AND DISCUSSION}

STM. Monocarboxylic Acid SAMs. Images for Ph-COOH are presented in Fig. 1. The layer appears uniform but, in contrast to all the other molecules studied, no specific features were discernible as exemplified by Fig. 1a. Numerous attempts to obtain high resolution were unsuccessful. At best some row type features, separated by about $5 \AA$ A could be observed which can be only vaguely seen in the original data (Fig. 1b) but become evident in the Fourier transform (inset in Fig. 1b) and the filtered image shown in Fig. 1c. This observation can be interpreted either as a lack of order in the SAM or as a lack of resolution. Anticipating the results from the NEXAFS measurements which indicate the presence of an ordered layer we favour the second interpretation. The difficulties to resolve the layer are, thus, caused by physisorbed molecules, which are picked up and dragged across the surface by the tip. This includes the possibility that they are generated by a tip induced detachment of a SAM molecule. An inferior stability of the benzoic acid SAM is consistent with our observation that rinsing with an ethanolic solution of $\mathrm{NaOH}$ causes extended damage of the layer, in contrast to the biphenyl and terphenyl SAMs where rinsing solved occasional imaging problems.
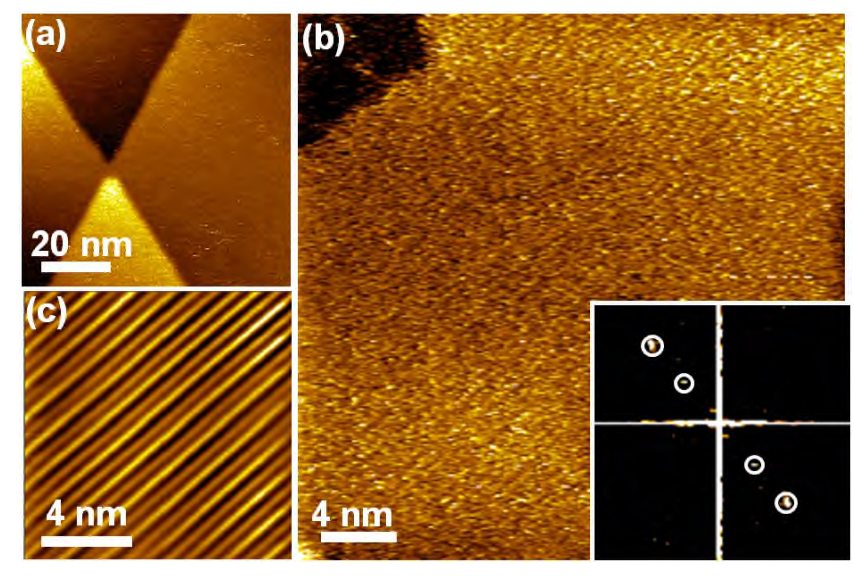

Figure 1. STM images of $\mathrm{Ph}-\mathrm{COOH}$ on UPD-Ag/Au/mica at different magnifications. The insert in (b) shows the Fourier transform of the SAM with diffraction spots highlighted. Image (c) shows part of a filtered image of the terrace in (b) containing linear row-like features.

Contrasting benzoic acid, SAMs of the biphenyl homologue $\mathrm{Ph}_{2}-\mathrm{COOH}$ could be imaged at high resolution as demonstrated in Fig. 2. Two structures labelled as $\alpha$ - and $\beta$-phase were observed with the former prevailing. On larger scale images such as the one shown in Fig. 2a lines running along different directions are seen which are characteristic of the $\alpha$-phase. Out of the six orientations reflecting the rotational and mirror symmetry of a (111) surface, four are seen in Fig. 2a. Lines labelled by non-primed numbers $(1,2)$ are related by a $120^{\circ}$ rotation as are the pairs indexed by primed numbers ( 2 , 3 '). Lines 2 and 2 ' meet at an angle of $\sim 40^{\circ}$ which reflects the fact that these lines are off the $<1 \overline{1} 0>$ direction by $\pm \mathbf{2 0} 0^{\circ}$ and related by mirror symmetry.

High resolution imaging of the $\alpha$-phase (Fig. 2c) reveals a structure which is characterised by rows of protrusions running along the $\langle 11 \overline{2}\rangle$ direction. The observed separation by a distance of $5.0 \pm 0.2 \AA$ suggests upright standing molecules which is corroborated by the spectroscopic measurements (vide infra). The separation corresponds to $\sqrt{3}$ times the Ag-Ag distance and, thus, indicates commensurability of the SAM structure along the $<11 \overline{2}>$ direction. Adjacent rows are shifted against each other such that the protrusions line up along a direction orientated at an angle of $\sim 70^{\circ}$ to the $\langle 11 \overline{2}>$ direction. The corresponding height profile A seen in Fig. $2 \mathrm{c}$ reveals a pattern repeating every third row. The structure can be described by a rectangular $5 \times \sqrt{3}$ unit cell which lacks mirror symmetry as inferred from Fig. 2c. The protrusions are essentially aligned along the diagonal of the unit cell. They vary substantially in height as seen from the profile A in Fig. $2 \mathrm{c}$ and their separation is not equidistant with values of 6.1, 4.7 and $4.5 \AA$ as determined from a unit cell averaged image. 

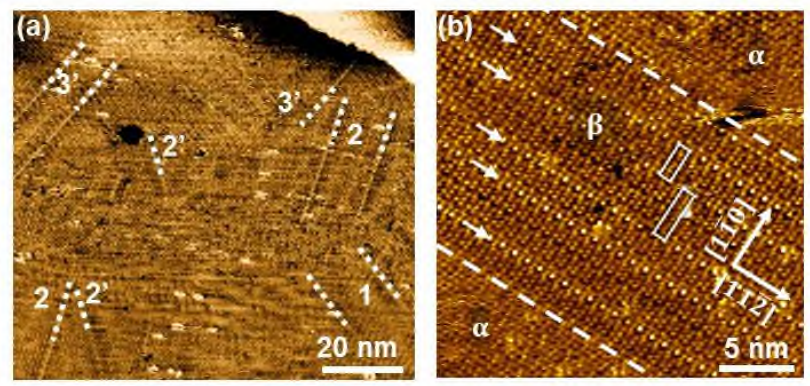

(c)
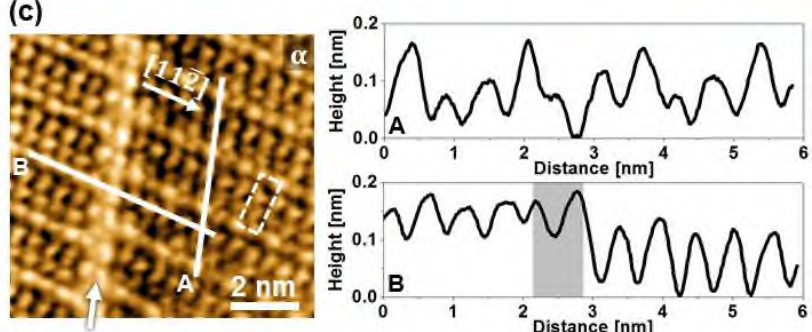

(d)

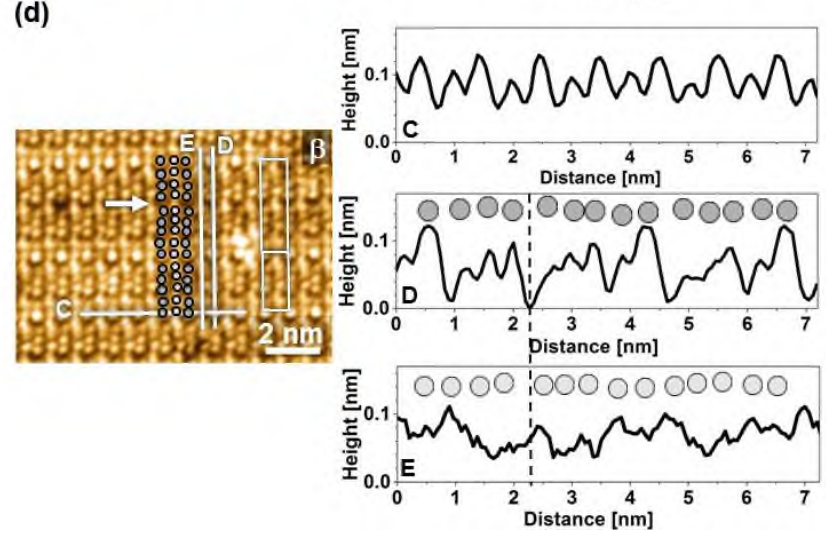

Figure 2. STM images of $\mathrm{Ph}_{2}-\mathrm{COOH}$ on UPD-Ag/Au/mica. (a) Large scale image with differently orientated domains of the $\alpha$-phase indicated by dotted lines. (b) Image showing coexistence of $\alpha$ and $\beta$ phases. Phase boundaries are marked by dashed lines. Arrows highlight rows of bright protrusions. Unit cells differing in size are marked by rectangles. (c) High resolution image of the $\alpha$ structure with a domain boundary marked by the arrow. Dashed rectangle indicates unit cell. Height profiles are along lines A and B. The position of the domain boundary in profile $B$ is indicated by the gray shaded area. (d) High resolution image of the $\beta$-phase. Protrusions across the two unit cells are marked by solid circles. Height profiles are along lines C-E. Solid circles in profiles D and E mark positions of protrusions as seen in image. Dashed line in profiles $\mathrm{D}$ and $\mathrm{E}$ marks the position of the arrow in (d).

The origin of the bright lines seen in Fig. 2a, which indicate the orientation of domains becomes clear looking at Fig. 2c which shows two domains shifted against each other as illustrated by the line profile B exhibiting different heights on either side of the domain boundary. The domain boundary itself is characterised by a double row of bright protrusions running $20^{\circ}$ off the $<1 \overline{1}$ o $>$ direction. This agrees with the line features highlighted in Fig. 2a.

The less abundant $\beta$-phase, seen in Fig. $2 b$ adjacent to the $\alpha$-phase, exhibits a more complex structure. Highlighted by white arrows, rows of bright protrusions separated by 1 $\mathrm{nm}$ run along the $<1 \overline{\mathbf{2}}>$ direction. A closer look reveals that these alternate with protrusions of lower height as inferred from the high magnification image (Fig. 2d) and the corresponding height profile $C$. Commensurability along the $<11 \overline{2}>$ direction is a common feature of the two phases which otherwise differ substantially. One difference is that the $\beta$-phase does not exhibit a significant shift between adjacent rows. Another one is the different periodicity along the $\langle 1 \overline{1} 0>$ direction which, furthermore, cannot be described by a single unit cell vector. The rows marked by the white arrows in Fig. $2 b$ are separated by either $23.4 \pm 0.6 \AA$ or $37.2 \pm 0.6 \AA$ which corresponds to 8 and 13 times the Ag-Ag distance. The occurrence of two periodicities and their large values indicate that the structure along the $<1 \overline{1} 0>$ direction is not fully commensurate. This is also reflected in the arrangement of the protrusions which is less regular compared to the $\alpha$-phase. Marking all protrusions within the two unit cells yields a rather irregular arrangement as seen from the ensemble of solid circles in Fig. 2d. This becomes even more clear looking at the height profiles $\mathrm{D}$ and $E$ which are shown together with the positions of the protrusions taken from Fig. 2 d.

From the features and dimensions observed in the STM images, the models depicted in Fig. 3 are suggested for the two phases. The protrusions appearing bright in the STM images and marking the corners of the unit cell are represented by the dark blue circles. The $\alpha$-phase is described by a $(5 \times \sqrt{3})$ structure unit cell with 3 molecules per unit cell, which yields a molecular footprint of $24 \AA^{2}$ $\left(4.17 \times 10^{14}\right.$ molecules $\left./ \mathrm{cm}^{2}\right)$. For the more complex $\beta$-phase we provide two structures according to the different distances seen between the rows of bright protrusions. One can be described by a rectangular $(8 \times 2 \sqrt{3})$ unit cell containing 10 molecules which gives $23 \AA^{2} /$ molecule. The larger unit cell is consistent with a $(13 \times 2 \sqrt{3})$ structure. With 16 molecules per unit cell this gives an area of 23.4 $\AA^{2} /$ molecule. A noticeable feature of this larger unit cell is a gap between the protrusions, located about half way along the long axis and not seen in the other structures. The molecular density of all three structures is within $5 \%$. Interestingly the more abundant $\alpha$-phase is slightly less dense than the $\beta$-phase. We stress at this point that there is no experimental information on the adsorption sites of 
the molecules and, thus, the substrate lattice should only be taken as reference for the registry of the SAM with the Ag surface. The issue of adsorption sites will be addressed below in the context of the DFT calculations.

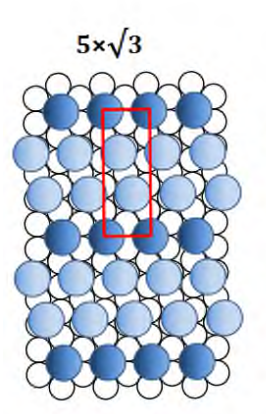

$\alpha$-phase

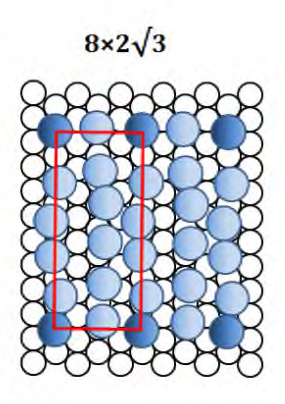

$\beta$-phase

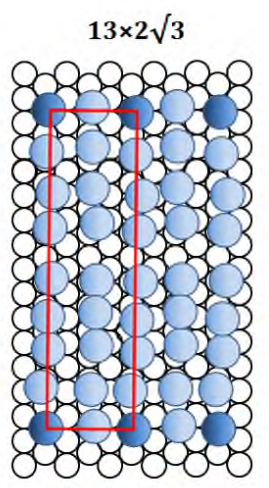

Figure 3. Models based on the STM data showing the arrangement of the $\mathrm{Ph}_{2}-\mathrm{COOH}$ molecules in the $\alpha$-phase and the two observed unit cells of the $\beta$-phase.

The SAM formed by $\mathrm{Ph}_{3}-\mathrm{COOH}$ is shown in Figure 4. The dimensions and the unit cell for this SAM match the $\alpha$ structure observed for $\mathrm{Ph}_{2}-\mathrm{COOH}$. Accordingly, as shown in Fig. $4 \mathrm{~b}$ and $4 \mathrm{c}$, mirror domains are present in addition to the three rotational domains as seen in Fig. 4a. In Fig. $4 \mathrm{c}$ the two mirror symmetric $(5 \times \sqrt{3})$ rectangular unit cells containing 3 molecules are highlighted. Notably, for this larger molecule only one structure is observed indicating a shift in the balance between intermolecular and molecule-substrate interactions.

While there is an overall excellent crystallinity of the SAM, we also observed small patches or molecular sized spots of lower tunneling contrast like those seen in Figs. $4 \mathrm{a}$ and $4 \mathrm{~b}$. We assign these to impurities consistent with the fact that the layer quality for most of the compounds studied improves pronouncedly upon recrystallisation of the substances. In addition to the periodic height modulation of the molecular lattice, there is another modulation which does not exhibit a particular pattern as most clearly seen in Figs. $4 \mathrm{~b}$ and $4 \mathrm{~d}$. We interpret this as a stress phenomenon similar to what has been observed for biphenyl-alkane thiols on $\mathrm{Au}^{57}$ Contrasting the case where aromatic thiols without alkane spacer form rather poorly ordered layers due to the substantial corrugation of the Au-S interaction potential which does not fit to the optimal molecular lattice, ${ }^{58}$ the weaker interaction between Ag and the carboxylate moiety seems to allow for a mismatch, thus, enabling a high crystallinity.
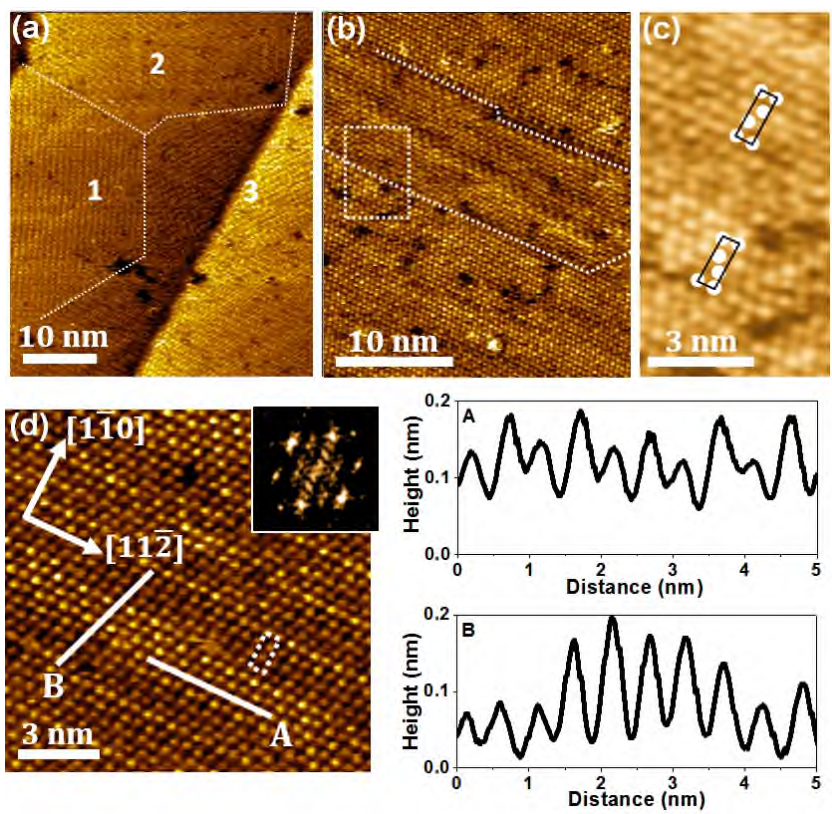

Figure 4. STM images showing the structure of $\mathrm{Ph}_{3}-\mathrm{COOH}$ on UPD-Ag/Au/mica. (a) Large scale image showing orientational domains with boundaries indicated by dotted lines. (b) Molecular resolution image showing multiple defects in the SAM. Dotted line marks boundary between mirror domains. (c) Enlarged image of the section enclosed by the dotted rectangle in (b) with mirror symmetric $(5 \times \sqrt{3})$ unit cells marked by the black rectangles. (d) Molecular resolution image with the Fourier transform (insert) and the unit cell highlighted by the white rectangle. Height profiles along lines A and B show the intermolecular distances.

Dicarboxylic acid SAMs. STM data for Ph- $(\mathrm{COOH})_{2}$ and $\mathrm{Ph}_{2}-(\mathrm{COOH})_{2}$ show that both dicarboxylic acid monolayers form highly crystalline SAMs. Notably, terephthalic acid SAMs as shown in Fig. 5 are routinely imaged down to molecular resolution which is in pronounced contrast to the difficulties encountered for benzoic acid presented in Fig. 1. On a large scale (Fig. 5a) six orientational domains are discernible which, as more clearly seen at higher magnification (inset of Fig. 5a), exhibit a row structure. Evaluation of the high resolution image shown in Fig. $5 \mathrm{~b}$ yields $4.1 \pm 0.3 \AA$ for the separation of the protrusions along the rows (profile $A$ ) which is a value comparable to the $\pi-\pi$ stacking distances observed for the sandwich configuration of benzene. ${ }^{59}$ Along the $B$ direction the protrusion are separated by $6.7 \pm 0.5 \AA$. As indicated in Fig. $5 \mathrm{~b}$ and evidenced in Fig. S1 which shows the SAM at a substrate step the rows are rotated by about $\pm 10^{\circ}$ against the $\langle 1 \overline{1}>$ direction, thus, explaining the occurrence of six domains. Line B runs $\sim 5^{\circ}$ off the $<1 \overline{1} 0>$ direction. It is noted that the very regular arrangement of 
the protrusions does not reveal any sign of pairing of rows or protrusions as observed for this molecule on $\mathrm{TiO}_{2}{ }^{26,60-}$ ${ }^{61}$ or $\mathrm{Cu}(100) .{ }^{27}$

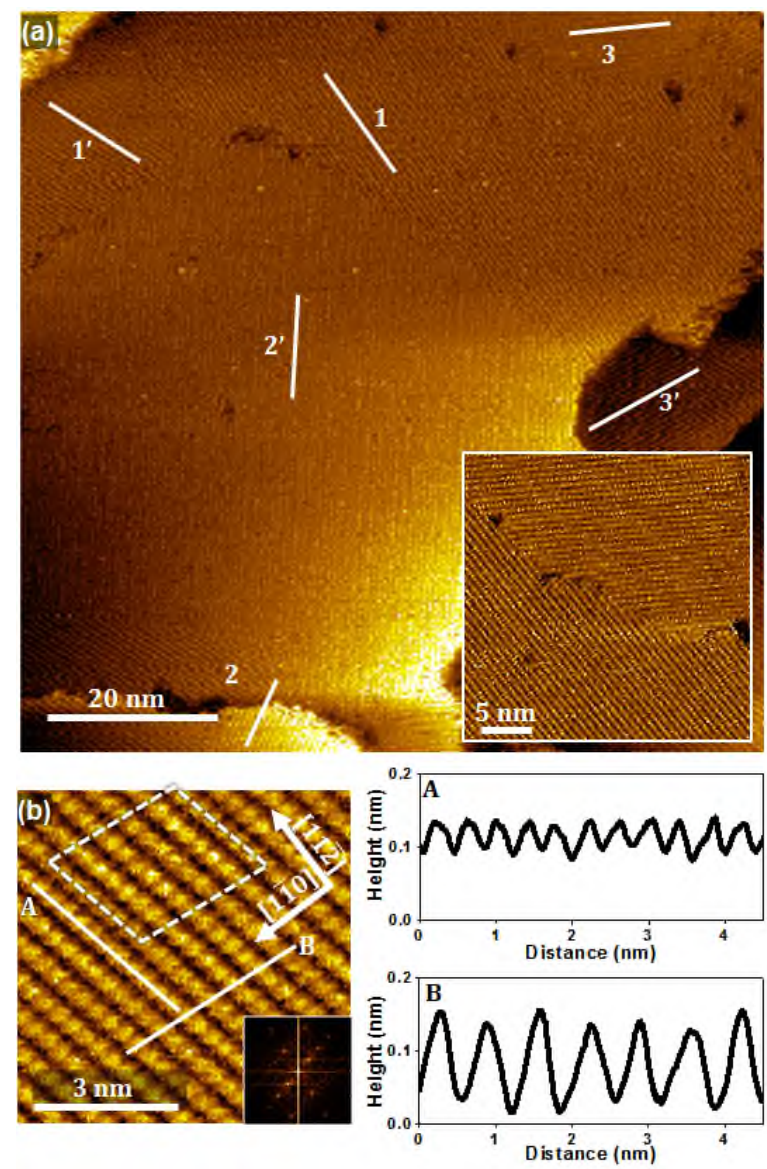

Figure 5. STM images of Ph- $(\mathrm{COOH})_{2}$ on UPD-Ag/Au/mica. (a) All 6 domain orientations are shown, with lines labelled 13 and ' '-3' indicating rotational and mirror domains. Inset: Two rotational domains detailing the row structure. (b) Molecular resolution image of the SAM with the Fourier transform in the insert and lines marking the height profiles shown. Dashed parallelogram shows unit cell presented in Fig. 6.

STM imaging of the $\mathrm{Ph}_{2}-(\mathrm{COOH})_{2}$ SAMs reveals an analogous picture as documented in Fig. S2. Exhibiting the same molecular packing as terephthalic acid the only observable difference is that the domain boundaries of $\mathrm{Ph}_{2}-(\mathrm{COOH})_{2}$ do not appear as sharply defined as in the case of $\mathrm{Ph}-(\mathrm{COOH})_{2}$ which we ascribe to a higher level of impurities present in the substance.

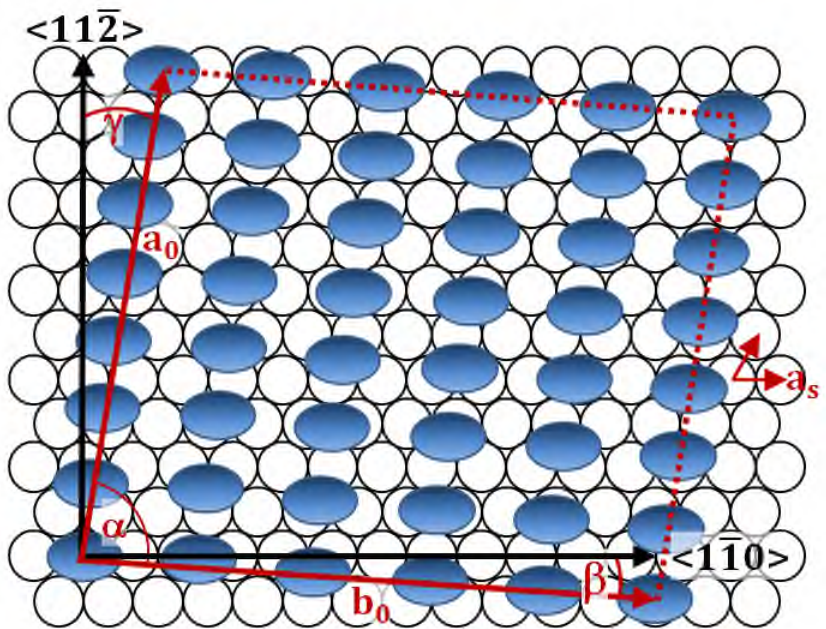

Figure 6. Model based on the intermolecular distances and angles measured from the STM data for the dicarboxylic acid SAMs showing the $\left(\begin{array}{cc}11 & -4 \\ -1 & 12\end{array}\right)$ unit cell. The unit cell vectors of the substrate $\left(a_{\mathrm{s}}\right)$ and adsorbate $\left(a_{\mathrm{o}}\right.$ and $\left.b_{\mathrm{o}}\right)$ are indicated.

Combining all of the information on the dicarboxylic acids, the structure depicted in Fig. 6 is suggested. We note that with the limited precision of the STM data it is not possible to unequivocally pin down the unit cell and decide whether the structure is commensurate or not. The suggested unit cell represents a commensurate structure with the smallest size compatible with the angles and distances measured. However, even this weakly commensurate one is of substantial size, well exceeding what has been reported so far for SAMs of oligophenylene based thiols or selenols. ${ }^{62,63}$ The unit cell is described by a $\left(\begin{array}{cc}11 & -4 \\ -1 & 12\end{array}\right)$ matrix and contains 35 molecules. The lengths of the unit cell vectors are $a_{0}=\sqrt{ } 93$ and $b_{0}=\sqrt{ } 133$ times the Ag-Ag distance of $2.89 \AA$. Orientated at angles of $\beta=4.5^{\circ}$ and $\gamma=9^{\circ}$ with respect to the $<11 \overline{2}>$ and $<1 \overline{1} 0>$ directions, thus, forming an angle of $\alpha=85.5^{\circ}$, these unit cell vectors are in very good agreement with the dimensions observed. The area of this unit cell amounts to $925.3 \AA^{2}$, thus yielding an area per molecule of $26.5 \AA^{2}$ which is $\sim 10 \%$ larger compared to the monocarboxylic acids. This unit cell is the one shown in Figs. 5b and Fig. S2c. An interesting point and difference to both the SAMs of monocarboxylic acids presented above and SAMs of oligophenylene thiols ${ }^{57,62,64}$ is the lack of contrast variation of the protrusions. For example, the $\mathrm{Ph}_{2}-\mathrm{COOH}$ SAM exhibits a pronounced variation in the apparent height of the protrusions of up to $0.5 \AA$ (Fig. $2 \mathrm{~d}$ ) which is not seen for $\mathrm{Ph}_{2}-(\mathrm{COOH})_{2}$. This is somewhat 
surprising considering, looking at Fig. 6, that there has to be a variation in the adsorption sites within the unit cell.
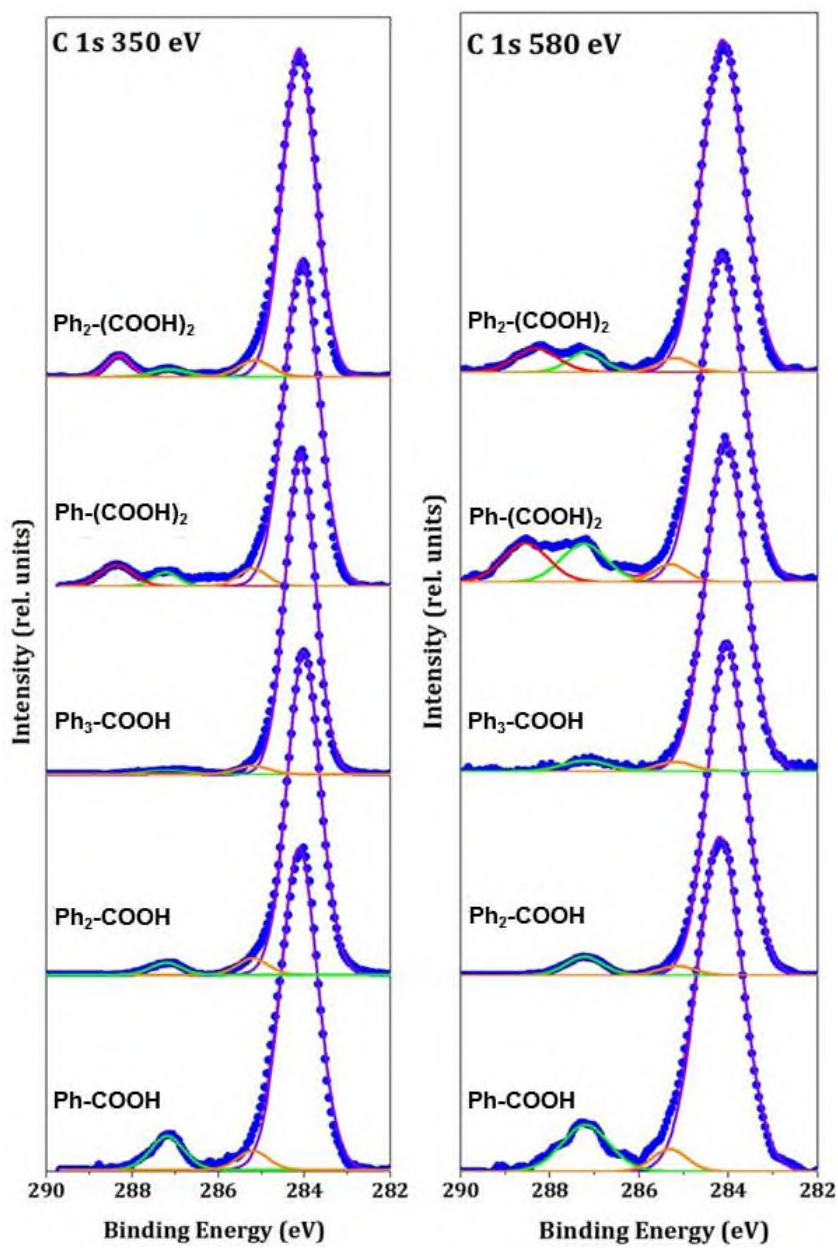

Figure 7. C is XP spectra of each of the SAMs on UPD-Ag/Au acquired at photon energies of $350 \mathrm{eV}$ (left) and $580 \mathrm{eV}$ (right). Components for the aromatic carbons (purple and orange), the carboxylate carbons (green) and the carboxylic acid carbons (pink) have been fitted. The blue scatter plots represent the original spectra. Intensities are normalised to the signal maximum of the main peak.

XPS. The $\mathrm{C}$ is and the $\mathrm{O}$ is XP spectra for all 5 of these monolayers are compiled in Figure 7 and Figure 8, respectively. The $\mathrm{C}$ is spectra have been decomposed into components characteristic of emissions from $\mathrm{COOH}$ $(\sim 288.5 \mathrm{eV}), \mathrm{COO}^{-}(\sim 287 \mathrm{eV})$ and the aromatic ring carbons (284-284.5 eV). ${ }^{24,}$ 35-37, 65-66 Following previous work on SAMs of molecules featuring an isophthalic acid moiety, all spectra were fitted with one component for each signal with the exception of the main emission, which has an additional small component located at $285.2 \mathrm{eV}$ with an area of 2-6 \% of the main peak. ${ }^{35-38}$ The origin of this small feature is not fully clear. On the one hand it is consistent with a residual carbonaceous impurity present after the preparation of the substrate. This is suggested by a comparison of the SAM spectra with the XP spectrum of a substrate prior to film formation (Fig. S3) which peaks at this energy. On the other hand it could also be a genuine feature of the aromatic system as discussed for aromatic thiol SAMs. ${ }^{67}$

For the monocarboxylic acid species, C is signals are present corresponding to the aromatic carbons and the carboxylate moiety. No signal is detected in the range of the free carboxylic acid, thus, contrasting the dicarboxylic acids which show peaks of both the carboxylate and free carboxylic acid moieties. In accordance with the dense packing seen in the STM images, we conclude that the molecules in all monolayers are bound to the silver through a carboxylate-metal bond and adopt an upright geometry. Hence, in the case of the monocarboxylic acids, the outer surface of the SAM is formed by an aromatic ring and whereas in the case of the dicarboxylic acids it is $\mathrm{COOH}$.

Comparison of the spectra acquired with a photon energy of $350 \mathrm{eV}$ and those acquired at $580 \mathrm{eV}$ provides additional information on the monolayer structure since the escape depth of the photoelectrons is significantly larger for the higher photon energy. This means that the groups buried at the metal-organic interface have an increased contribution when using higher photon energies. ${ }^{37}$ Looking at the spectra in Figure 7 , for all SAMs the intensity of the carboxylate signal relative to the main carbon peak increases on going from $350 \mathrm{eV}$ to $580 \mathrm{eV}$, which is another indication that the carboxylate is located at the SAM-substrate interface. Furthermore, in the case of the dicarboxylic acids the $\mathrm{COOH} / \mathrm{COO}$ - signal ratio decreases with increasing photon energy. The corresponding numbers are compiled in Table S1.

Analysis of the $\mathrm{O}$ is XP spectra for the monolayers of $\mathrm{Ph}$ $\mathrm{COOH}, \mathrm{Ph}_{2}-\mathrm{COOH}$ and $\mathrm{Ph}_{3}-\mathrm{COOH}$ presented in Fig. 8 is straightforward as only one signal is present, representing the carboxylate oxygens $(\sim 530.4 \mathrm{eV})$. For $\mathrm{Ph}-(\mathrm{COOH})_{2}$ and $\mathrm{Ph}_{2}-(\mathrm{COOH})_{2}$, the spectra can be decomposed into three components corresponding to $\mathrm{COO}^{-}(\sim 530.6 \mathrm{eV})$, $\mathrm{C}=\mathrm{O}(\sim 531.5 \mathrm{eV})$ and $\mathrm{C}-\mathrm{OH}(\sim 533.5 \mathrm{eV}){ }^{37,}, 65,68$ When fitting the spectra for the dicarboxylic acids, the hydroxyl and carbonyl oxygens of the free carboxylic acid group were set to a stoichiometric ratio of 1 . This assumes that other oxygen species originating from the substrate preparation are displaced upon SAM formation. Comparing spectra of the monocarboxylic acid SAMs with the spectrum of the substrate (Fig. $\mathrm{S}_{3}$ ) this assumption 
seems justified as the features with a binding energy above $523 \mathrm{eV}$ seen in the native substrate are absent in the SAM spectra.

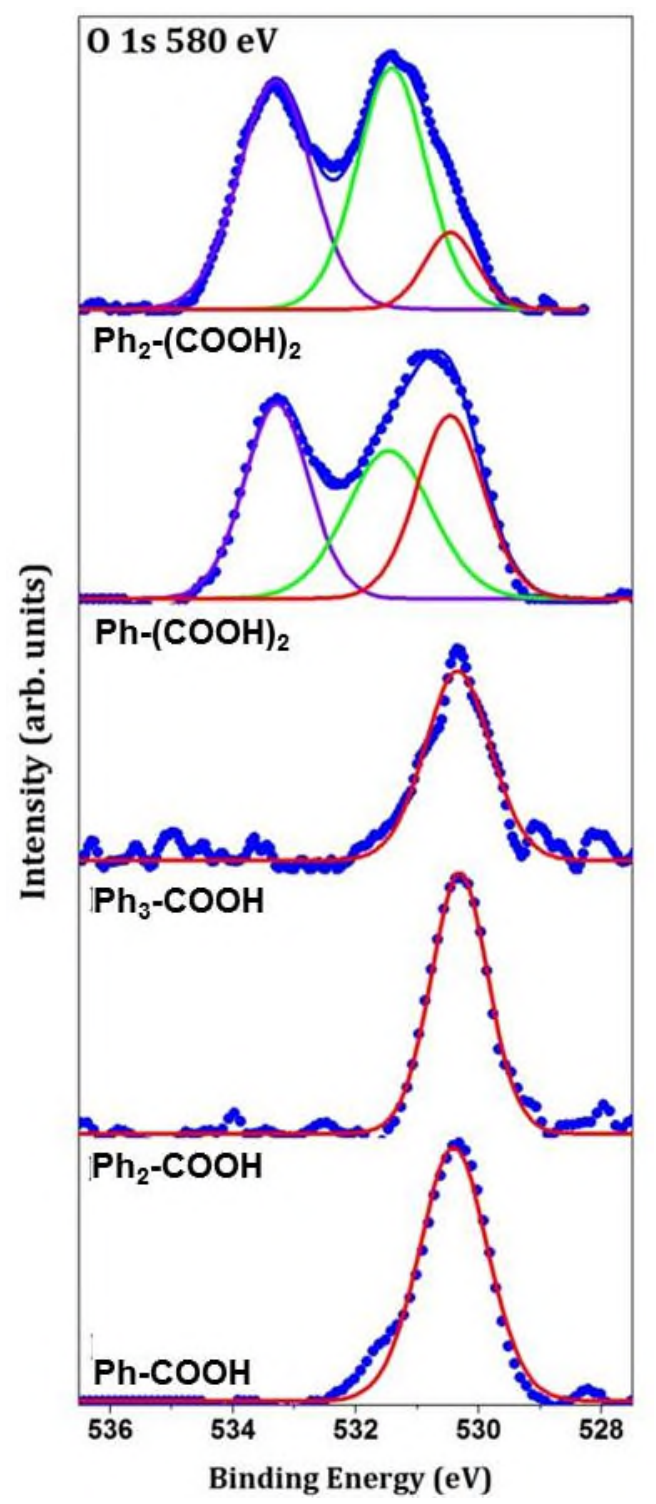

Figure 8. O is XP spectra for each SAM on UPD-Ag/Au/mica acquired with a photon energy of $580 \mathrm{eV}$. Components for the carboxylate oxygens (red), the carbonyl oxygens (green) and the hydroxyl oxygens (purple) have been fitted. The blue scatter plots represent the original spectra.

The $\mathrm{O}$ is spectra further substantiate the conclusions drawn from the $C$ is data. The absence of any signals for hydroxyl or carbonyl oxygens in the spectra for the monocarboxylic acids fits the model of a metalcarboxylate binding motif with no free carboxylic acid present. Also, the intensity of the carboxylate signal decreases successively with increasing length of the molecules which is reflected by the decreasing signal to noise ratio at going from $\mathrm{Ph}-\mathrm{COOH}$ to $\mathrm{Ph}_{2}-\mathrm{COOH}$ and to $\mathrm{Ph}_{3}-\mathrm{COOH}$.

In the case of the dicarboxylic acids, there are signals corresponding to both carboxylate and free carboxylic acid groups. The strong attenuation of the carboxylate signal for the SAM of the longer $\mathrm{Ph}_{2}-(\mathrm{COOH})_{2}$ molecule compared to $\mathrm{Ph}-(\mathrm{COOH})_{2}$ is another manifestation of the carboxylate being buried at the metal-organic interface.

NEXAFS spectroscopy. The C K-edge and O K-edge NEXAFS data for the series of mono and dicarboxylic acids are presented in Fig. 9. On the left, the spectra acquired at an incident angle of the primary X-ray beam $55^{\circ}$ are shown. At this "magic angle" of incident radiation, the spectra contain purely electronic structure information about the monolayer, with no contribution from the effects of molecular orientation. ${ }^{47}$ The panels on the right show the difference spectra obtained from subtracting the spectra obtained at grazing incidence $\left(20^{\circ}\right)$ of the X-ray radiation from those obtained at normal incidence $\left(90^{\circ}\right)$. These panels reveal information on the orientation of the molecular orbitals and, consequently, the molecules.

The most pronounced resonances in the NEXAFS spectra have been assigned on the basis of literature data. ${ }^{47,69}$ For the C K-edge, all spectra contain a dominant resonance from transitions into the $\pi^{*}$ orbital of the phenyl rings at $285.0 \mathrm{eV}\left(\pi^{*}{ }_{\mathrm{ph}}\right)$ and into the $\pi^{*}$ orbital of the $\mathrm{COOH} / \mathrm{COO}$-groups at $\sim 288.5 \mathrm{eV}\left(\pi^{*}{ }_{\mathrm{COOH}}\right)$.

A splitting of the $\pi^{*}$ ph resonance associated with the additional $\mathrm{COOH}$ substitution ${ }^{52}$ is clearly seen in the spectra of the $\mathrm{Ph}_{2}-(\mathrm{COOH})_{2}$ and especially $\mathrm{Ph}-(\mathrm{COOH})_{2}$ SAMs. The $\pi^{*} \mathrm{COOH}$ resonance is hardly perceptible in the spectra of the $\mathrm{Ph}_{2}-\mathrm{COOH}$ and $\mathrm{Ph}_{3}-\mathrm{COOH}$ SAMs due to the attenuation of the respective signal, supporting once more the well-defined character of these monolayers. The $\mathrm{O}$ K-edge spectra are dominated by the $\pi_{\mathrm{COOH}}^{*}$ resonance at $532.3 \mathrm{eV}$, accompanied by an additional feature at $\sim 544$ $\mathrm{eV}$ related to the transition into $\sigma^{*}$ orbital. ${ }^{37,69}$

In all cases, the difference spectra exhibit a prominent linear dichroism, indicating a high level of orientational order within the SAMs. The signs of the characteristic peaks in the difference spectra of all monolayers suggest, in accordance with the orientations of the respective $\pi^{*}$ and $\sigma^{*}$ orbitals, that the molecules have an upright orientation. This conclusion is consistent with the STM 
data
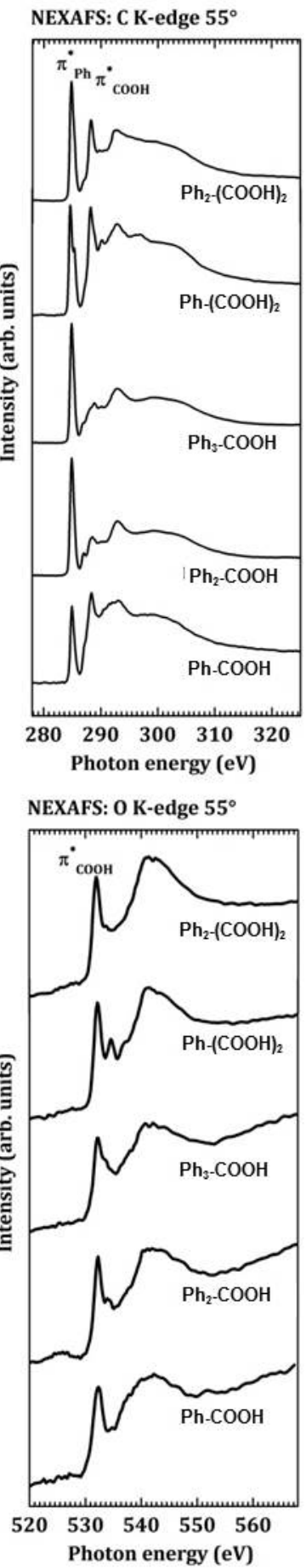

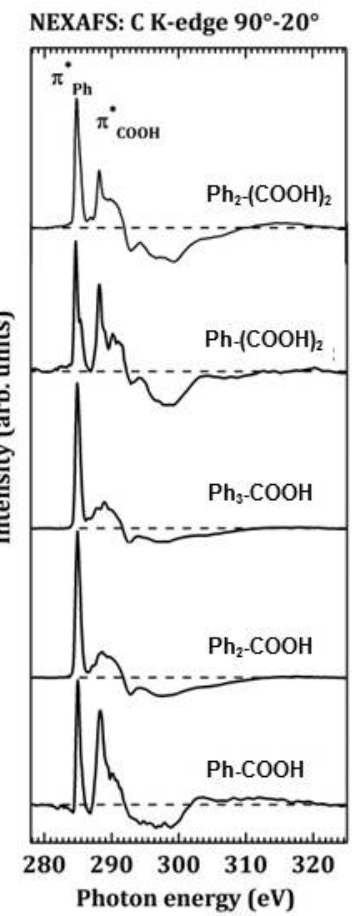

NEXAFS: $0 \mathrm{~K}$-edge $90^{\circ}-20^{\circ}$

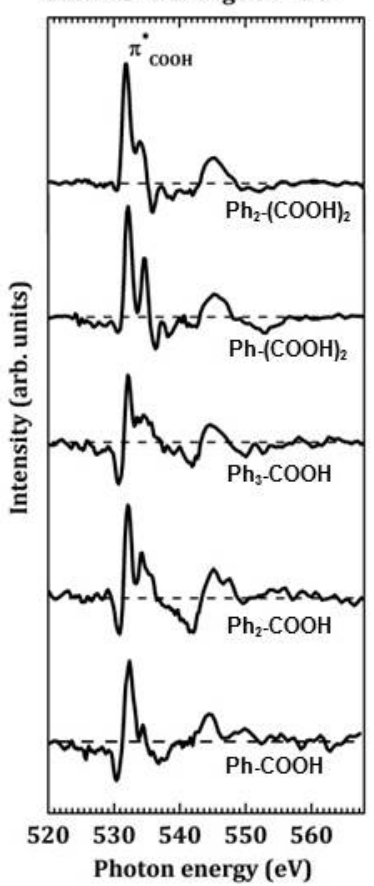

Figure 9. $\mathrm{C}$ (top) and $\mathrm{O}$ (bottom) K-edge NEXAFS spectra of each SAM on UPD-Ag/Au/mica. Left panels: spectra acquired at an X-ray incidence angle of $55^{\circ}$. Right panels: difference spectra resulting from subtracting the spectra acquired at an $\mathrm{X}$-ray incidence angle of $20^{\circ}$ from those acquired at $90^{\circ}$. The most prominent resonances are assigned. The dashed lines in the difference spectra correspond to zero.

where the distances between protrusions are not compatible with a flat-lying arrangement. Notably, there is no substantial difference in the dichroism between SAMs of $\mathrm{Ph}-\mathrm{COOH}$ and the other molecules. Together with the observation that only carboxylate but no carboxylic acid peaks are seen in the XPS, this indicates that also the Ph-COOH SAM is well ordered. Hence it is concluded that the lack of resolution when investigating the surface with STM (Fig. 1) is not a sign of disorder but relates to the imaging process.

Table 1. NEXAFS derived orientation of $\pi^{*}$ orbitals of the phenyl rings and carboxylic acid groups for the SAMs on $\mathrm{Ag}$ modified $\mathrm{Au} / \mathrm{mica}$. Error margins are $\sim \pm 3^{\circ}$ and $\sim \pm 5^{\circ}$ for the $\mathrm{C}$ K-edge and $\mathrm{O} \mathrm{K}$-edge, respectively.

\begin{tabular}{llll}
\hline \multicolumn{4}{l}{ Tilt angle $\rho^{\circ}{ }^{\circ}$} \\
& Ring & \multicolumn{2}{l}{ COOH/COO } \\
\cline { 3 - 4 } & (C K-edge) & (C K-edge) & (O K-edge) \\
\hline $\mathrm{Ph}-\mathrm{COOH}$ & 69 & 69 & 64 \\
$\mathrm{Ph}_{2}-\mathrm{COOH}$ & 81 & 70 & 65 \\
$\mathrm{Ph}_{3}-\mathrm{COOH}$ & 80 & 73 & 65 \\
$\mathrm{Ph}^{-}(\mathrm{COOH})_{2}$ & 65 & 64 & 65 \\
$\mathrm{Ph}_{2}-(\mathrm{COOH})_{2}$ & 71 & 67 & 66 \\
\hline
\end{tabular}

The quantitative evaluation of the NEXAFS data yields the orientation of the transition dipole moments (TDMs) of the $\pi^{*}$ resonances which, as illustrated in Fig. 10, is given by the angle $\rho$ between the $\mu$ vectors and the $\mathrm{z}$-axis. Comparison of the values which are compiled in Table 1 reveals two points. Firstly, the values for the $\mathrm{COOH} / \mathrm{COO}^{-}$resonances at the $\mathrm{C}$ and $\mathrm{O}$ K-edges are, within the experimental error, identical for all compounds. Secondly, there are two sets of values for the orientation of the TDMs of the aromatic moieties. The dicarboxylic acids and benzoic acid (set I) exhibit, to a first approximation, the same orientation of the TDMs for both the aromatic rings and the carboxylic acid groups. In contrast, the $\rho$-values for the biphenyl and terphenyl moieties of the monocarboxylic acids (set II) are larger by about $10^{\circ}-15^{\circ}$ whereas the values for the carboxylic acid groups is the same as for set I. Postponing a detailed discussion of the variation in the $\rho$ values to the section of the DFT calculations we note at this point that the experimentally determined values represent average values from different molecules which might be in conformationally different states. It should also be recalled that due to the significant attenuation of the electron yield signal from buried moieties the tabulated 
values represent a weighted average. In particular, from phenyl to terphenyl there is a gradient in the contributions of the different rings to $\pi^{*}$ Ph resonance. In the case of the dicarboxylic acids the anchoring carboxylate groups at the SAM-substrate interface contribute progressively less to the $\pi^{*} \mathrm{COOH}$ resonance than the carboxylic acid group at the SAM-ambient interface when going from phenyl to biphenyl. Another consequence of the molecule dependent attenuation is that for the monocarboxylic acids,

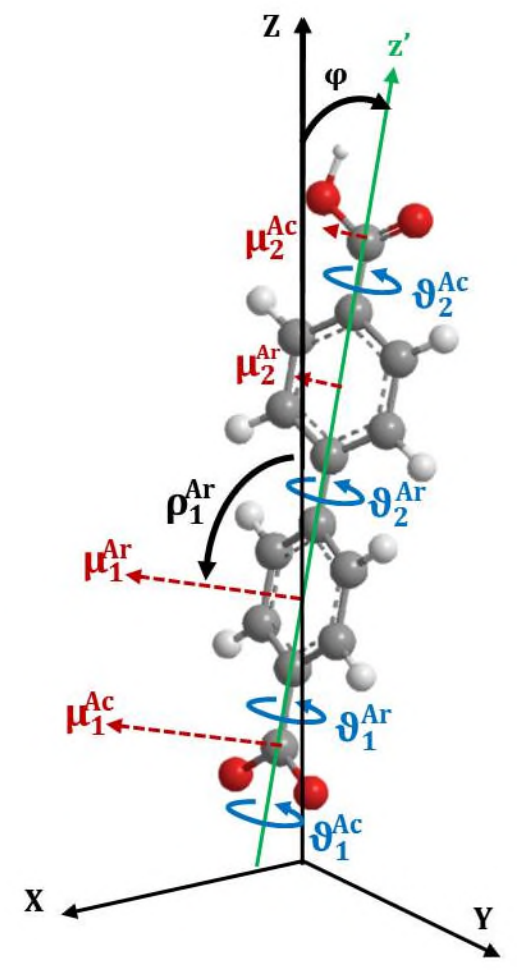

Figure 10. Definition of angles which correlate the orientation of the transition dipole moments $\mu_{i}^{R}$, expressed by angle $\rho_{i}^{R}$, with the orientation of the molecules defined by the tilt angle $\phi$ of the molecular axis (z') and twist angles $\vartheta_{i}^{R}$ of the individual moieties. $\vartheta_{i}^{R}=0$ if the plane of the moiety is orthogonal to the $z, z$ ' plane. The $x, y$-plane defines the surface.

especially for the $\mathrm{Ph}_{2}-\mathrm{COOH}$ and $\mathrm{Ph}_{3}-\mathrm{COOH}$ films, the precision of the values for the carboxylate moiety is limited as, in particular, suggested by the differences in the values determined for the $\mathrm{C}$ and $\mathrm{O}$ K-edges.

DFT Calculations. $\mathrm{Ph}_{2}-\mathrm{COOH}$ and $\mathrm{Ph}_{2}-(\mathrm{COOH})_{2}$ SAMs were modelled as for these two monolayers a complete set of spectroscopic and molecularly resolved microscopic data is available. A major point was to gain insight into the possible role of hydrogen bonding between $\mathrm{COOH}$ groups. Exhibiting a pronounced configurational flexibility $^{70}$ its influence on the molecular arrangement has been studied for terephthalic acid on $\mathrm{TiO}_{2}{ }^{59}$ Compared to SAMs of trimesic acid ${ }^{37}$ and biphenyltricarboxylic acid ${ }^{38}$ on $\mathrm{Ag}$ for which $\mathrm{COOH}$ based intermolecular interactions were identified as a crucial structure determining element, the orientation of the $\mathrm{COOH}$ groups and, thus, options for intermolecular interactions are substantially different for the SAMs presented here. Given the conformational and orientational degrees of freedom of the molecules as detailed in Fig. 10, another point of interest was how the arrangements of the phenyl and carboxylic moieties map onto the experimentally determined ensemble averaged value for the respective TDMs.

At this point it is appropriate to stress the limitations of the approach taken here. Firstly, compromises in the size and shape of the unit cells had to be made to limit the computational effort. Secondly, the choice of the starting geometries involved some arbitrariness. The main point was to place the molecules such that the carboxylate adopts a symmetric bidentate geometry in agreement with the XPS data and, lacking experimental information for $\mathrm{Ag}$, choosing on-top sites in analogy to carboxylic acids on $\mathrm{Cu}^{71}$. Conducting geometry optimisations from different starting structures, with the carboxylic oxygen atoms on top, bridge or hollow sites, and different twist angles for the phenyl rings and carboxylic acid groups, we observed that variations of the starting geometries could produce stable structures very close in energy but notable differences in the molecular orientation and conformation which is in line with our observation of coexisting phases for $\mathrm{Ph}_{2}-\mathrm{COOH}$ (see Fig. 2). Given the complexity of the potential energy surface and the number of degrees of freedom, however, we do not claim to have covered all possible conformations. Since a more systematic exploration of the configurational landscape of the SAMs was well beyond the scope of the work presented here, the results and discussion presented here should be understood as rather an illustration of some general features of these SAMs than an exact quantitative description of the systems.

For the $\mathrm{Ph}_{2}-\mathrm{COOH}$ SAM, the structure of the $\alpha$-phase was chosen. It is the dominating phase seen in the STM experiments and described by a well defined $(5 \times \sqrt{3})$ unit cell containing three molecules, in contrast to the $\beta$-phase 
for which a coexistence of differently sized unit cells was observed (see Fig. 3). The structure resulting from the DFT calculations is shown in Fig. 11 which, for better visualization, displays the SAM in sections of different fragments of the molecules. The geometry optimisation started from the configuration shown in the inset which was chosen based on the pattern seen in STM, assuming an on-top bidentate geometry and using the conformation of the molecule obtained from gas phase calculations of the isolated molecule.

The geometry optimisation resulted in a significant restructuring. The molecules, arranged in rows aligned with the $<11 \overline{2}>$ directions of the Ag substrate differ from the initial configuration both in their adsorption geometry and conformation of the biphenyl units. As seen from the rightmost section of Fig. 11 the carboxylate moieties

adopt three different adsorption geometries. One is a rather symmetric bidentate (row 1 ), the second one (2) is characterised by bridge sites whereas the third one (3)

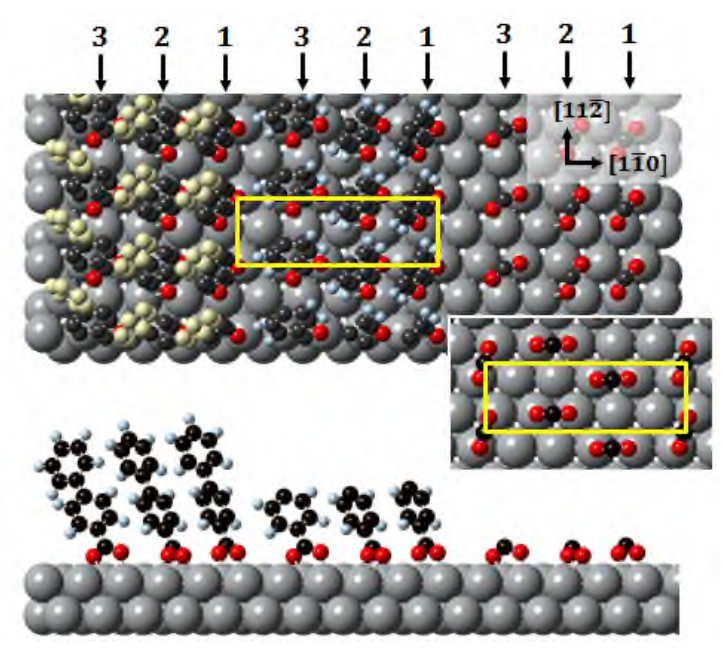

Figure 11. Top and side views of DFT model of the $\mathrm{Ph}_{2}{ }^{-}$ $\mathrm{COOH}$ SAM on a metal slab consisting of 3 layers of $\mathrm{Au}$ atoms (not shown) and 2 layers of $A g$ atoms. The $(5 \times \sqrt{3})$ unit cell of the $\alpha$-phase is indicated by the yellow rectangle. The SAM is presented in different sections each displaying different fragments of the molecules as seen from the side view. In the leftmost section showing the complete molecule, the hydrogen atoms have been omitted for clarity in the top view. Also different colors have been chosen for the bottom (black) and top (yellow) benzene rings. Inset in top view shows initial adsorption geometry.

combines on-top and bridge sites. It is noted that the significant change in the adsorption geometry does not substantially affect the molecule-substrate interaction energy. This is concluded from calculations with a unit cell containing one molecule and being sufficiently large for intermolecular interactions to be negligible. The difference in energy between the top-bridge and all-top configuration was found to be less than $1 \mathrm{~kJ} / \mathrm{mol}$ which indicates that the change in adsorption sites and, thus, the film structure is driven by the intermolecular interactions. From the second section, which shows the benzoic acid fragment, it is seen that, like in the gas phase, the bottom aromatic ring is essentially coplanar with the carboxylate group. The third section, displaying the full molecule, reveals that the conformation of the biphenyl moiety deviates significantly from the one found for the gas phase. The twist between the two rings is not only different from the $40^{\circ}$ of the isolated molecule but also pronouncedly dependent on the molecules with values of $20^{\circ}$ (row 1 ), $0^{\circ}$ (2) and $50^{\circ}$ (3). From the calculated torsion potential (see Fig. $\mathrm{S}_{5}$ ) this corresponds to an increase in energy of about 3,8 and $1.5 \mathrm{~kJ} / \mathrm{mol}$. Correspondingly, the tilt angle $\varphi$ (see Fig. 10 for definition) is also different for

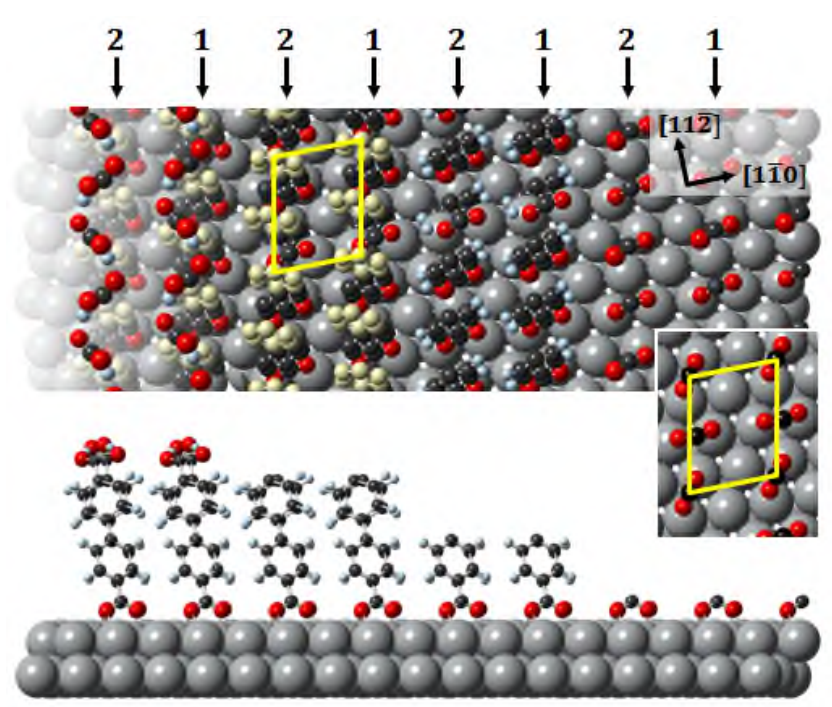

Figure 12. Top and side views of DFT model of the $\mathrm{Ph}_{2}$ $(\mathrm{COOH})_{2}$ SAM on a metal slab consisting of 3 layers of $\mathrm{Au}$ atoms (not shown) and 2 layers of Ag atoms. The $(2 \times \sqrt{7})$ unit cell is indicated by the yellow parallelogram. To illustrate the structure the layer is presented in different sections each displaying different fragments of the molecules as seen from the side view. In the leftmost section, which shows the complete molecule, the two benzene rings have different colors (black: bottom ring, yellow: top ring). For clarity the hydrogen atoms have also been omitted in this section. 
the three molecules with values of the $20^{\circ}$ (row 1), $25^{\circ}(2)$ and $35^{\circ}(3)$.

Contrasting the case of $\mathrm{Ph}_{2}-\mathrm{COOH}$ where the experimentally observed unit cell could be modelled at least for the $\alpha$-phase, the calculations of the $\mathrm{Ph}_{2}-(\mathrm{COOH})_{2}$ SAM are based on a crude approximation as the unit cell chosen is quite different from the experimentally observed structure whose $\left(\sqrt{93}_{93} \times \sqrt{133}_{13}\right)$ unit cell is prohibitively large to be treated computationally. However, the dimensions along the direction where the molecules are closely spaced and, thus, H-bonding can be expected is well matching the distance observed experimentally.

The structure obtained from the calculations is depicted in Fig. 12. It is based on an oblique $(2 \times \sqrt{ } 7)$ unit cell containing two molecules and forming an angle of $79.1^{\circ}$ between the unit cell vectors (compared to $85.6^{\circ}$ of the experimentally observed structure). In contrast to the monocarboxylic acid, the carboxylate moieties of the two molecules exhibit the same adsorption geometry with both oxygen atoms in an asymmetric bridge site position. As for the monocarboxylic acid the bottom aromatic ring is essentially coplanar with the anchor moiety. The top aromatic rings of both molecules are twisted against the bottom ring by about $25^{\circ}$, i.e., somewhat less compared to the free molecule.

While the aromatic moieties and the head groups are arranged in an almost identical fashion in both molecules of the unit cell, a pronounced difference between them exists with respect to the terminal carboxylic acid groups. This is highlighted in row 2 of the leftmost section of Fig. 12 which shows them at enhanced contrast. They are arranged in a zig-zag fashion which means that the hydrogens point to the oxygen of the neighboring $\mathrm{COOH}$ group. The $\mathrm{O}$... O distance of $\sim 2.7 \AA$ agrees well with the typical distances of hydrogen bonding found in carboxylic acids. $^{72}$ A consequence of the hydrogen bonded arrangement is that the $\mathrm{COOH}$ groups are significantly twisted against the top aromatic rings. Since these are parallel the twist angles are very different for the two $\mathrm{COOH}$ groups with values of $\sim 135^{\circ}$ and $\sim 45^{\circ}$, respectively. Considering that the coplanar geometry of the $\mathrm{COOH}$ group and the ring is the preferred one for the isolated molecule, a torsion by the angles found for the structure depicted in Fig. 12 costs about $10 \mathrm{~kJ} / \mathrm{mol}$ (see Fig S6). Even though this reduces the gain in energy by intermolecular hydrogen bonding, there is a net stabilisation of the SAM structure by the $\mathrm{COOH}$ groups. This agrees well with our experimental observations that terephthalic acid forms a highly crystalline, stable SAM which can be imaged at molecular resolution (Fig. 5) whereas the benzoic acid SAM (Fig. 1) lacks the stability for high resolution imaging. Even though different from the chain like $\mathrm{H}$ bonding discussed here, the structural features seen in STM/AFM images of terephthalic acid on $\mathrm{TiO}_{2}{ }^{26,60}$ and $\mathrm{Cu}(100)^{27}$ have also been explained by intermolecular $\mathrm{H}$ bonding. Calculations for $\mathrm{Ph}-(\mathrm{COOH})_{2}$ on $\mathrm{TiO}_{2}$ yield a pairwise interaction of $\mathrm{COOH}$ groups which are aligned with the aromatic ring, ${ }^{61}$ whereas a twisted conformation was suggested for the case of $\mathrm{Cu}(100)$. In this context it is noted that the case discussed here and the one on $\mathrm{Cu}(100)$ differs from the case of 1,2,4-benzenetricarboxylic acid on $\mathrm{Cu}(100)^{24}$ which also involves hydrogen-bonding of a carboxylic acid moiety in an out-of-plane conformation. However, in this case the out-of-plane geometry is a consequence of sterical hindrance between adjacent COOH groups. ${ }^{73}$

Turning now to the correlation between the conformations/orientations of the molecules in the calculated structures and the orientation of the TDMs experimentally determined by NEXAFS and represented by $\rho$, it is seen from Fig. 10 that, for a particular moiety, $\rho$ depends on both the tilt angle $\varphi$ and the twist angle $\vartheta$ which leaves an ambiguity in the determination of a configuration unless differently oriented TDMs with a fixed correlation can be probed. ${ }^{74}$ Furthermore, as a spatially averaging technique NEXAFS yields a $\rho$ value for a specific TDM which is the weighted average according to

$<\rho^{R}>=\cos ^{-1}\left(\frac{1}{\sum_{j=1}^{M} \sum_{i=1}^{N} g_{i, j}^{R}} \sum_{j=1}^{M} \sum_{i=1}^{N} g_{i, j}^{R} \cos \vartheta_{i, j}^{R} \sin \varphi_{i, j}^{R}\right)$

where the index $i$ labels the individual moieties in a molecule (e.g. the two aromatic rings) and the index $j$ numbers the molecules in the unit cell. $g_{i, j}$ is a weighting factor which takes into account that due to the limited escape depth of the electrons the contribution of a moiety to the total signal depends on its position within the layer. It is a relative number quantifying how much the signal from a more buried moiety is attenuated compared the one attenuated least (e.g. $\mathrm{COO}^{-}$vs $\mathrm{COOH}$ ).

Calculating the twist and tilt angles $\vartheta$ and $\varphi$ from the atomic coordinates as outlined in the Supporting Information, the $\rho$ values are compiled in Table 2 for i) the individual moieties, ii) the average of one molecule (where applicable) and iii) the average over all molecules 
of the unit cells. It also contains calculations for two different values of the attenuation factor $g$.

Looking at Table 2 two things are worth noting. Firstly, for the monocarboxylic acid, unlike the dicarboxylic acid, there is a substantial variation in the orientation of the benzene rings both across the different molecules and between the top and bottom phenyl rings. This variation is largest $\left(17^{\circ}\right)$ for molecule 3 . This, on the one hand, suggests that the SAM structure can well deviate from the usually assumed uniform orientation and coplanar conformation of the phenylene moieties. This argument has also been given preference over electronic effects in the interpretation of NEXAFS spectra of pyridine phenylene thiol where the experimental spectrum is best described by simulations assuming a twist between the two aromatic rings. ${ }^{75}$ On the other hand, the derived intramolecular twist angles in the SAMs are noticeably smaller than those observed for the respective moieties in the isolated molecule. Secondly, even though the effect of attenuation is overall rather small for the averaged values it can be more substantial or even show opposite trends depending on the exact orientation of the moieties. Taking the case of the carboxylic acid/carboxylate groups of $\mathrm{Ph}_{2}-(\mathrm{COOH})_{2}$ there is a minimal decrease in $\rho$ for molecule 1 whereas for molecule 2 the value increases when increasing the attenuation.

Table 2. Tilt angles $\rho$ (rounded to the nearest integer) of the TDMs of the $\pi^{*}$ resonances calculated from the DFT structures using eq. (1). Both individual and averaged (Avg) values for the phenyl rings and carboxylic acid groups are presented. $\mathrm{g}$ is the weighting factor as defined in eq. (1).

\begin{tabular}{|c|c|c|c|c|c|c|c|c|}
\hline \multicolumn{9}{|c|}{ Tilt angle $\rho\left[^{\circ}\right]$} \\
\hline & & \multicolumn{4}{|c|}{$\mathrm{Ph}_{2}-(\mathrm{COOH})_{1}$} & \multicolumn{3}{|c|}{$\mathrm{Ph}_{2}-(\mathrm{COOH})_{2}$} \\
\hline & & \multicolumn{4}{|c|}{ molecule } & \multicolumn{3}{|c|}{ molecule } \\
\hline & & 1 & 2 & 3 & Avg & 1 & 2 & Avg \\
\hline & & & & & $1-3$ & & & $1+2$ \\
\hline $\operatorname{Ar}(\mathrm{t}$ & op) & 66 & 71 & 76 & 71 & 71 & 72 & 71 \\
\hline $\operatorname{Ar}(\mathrm{b}$ & ottom) & 65 & 71 & 59 & 65 & 72 & 71 & 72 \\
\hline \multirow{2}{*}{ Avg } & $g=1$ & 66 & 71 & 68 & 68 & 71 & 72 & 71 \\
\hline & $\mathrm{g}=0.4$ & 66 & 71 & 72 & 70 & 71 & 72 & 71 \\
\hline \multicolumn{2}{|c|}{ COO- } & 65 & 71 & 65 & 67 & 73 & 72 & 72 \\
\hline \multicolumn{2}{|c|}{$\mathrm{COOH}$} & & & & & 67 & 85 & 76 \\
\hline \multirow{2}{*}{ Avg } & $g=1$ & & & & & 70 & 78 & 74 \\
\hline & $g=0.3$ & & & & & 69 & 82 & 75 \\
\hline
\end{tabular}

Comparing the calculated models with the experimental data highlights a general issue related to the interpretation of the experimental data. In the ideal case features observed experimentally are directly mirrored in the calculated models, thus, allowing for a more detailed interpretation. An example is the structure of the monocarboxylic acid $\mathrm{Ph}_{2}-\mathrm{COOH}$ (Fig. 11) for which the calculations yield variations in tilt angles and conformations for the three different molecules in the unit cell. This agrees well with STM images where a variation in height by about $1 \AA$ and non-equidistant separations of the protrusions are observed for the monocarboxylic acids (Figs. 2 and 4). However, there is another rather fundamental aspect to this which is the reduction in information associated with averaged spectroscopic information such as the orientation of TDMs. This is pinpointed by $\mathrm{Ph}_{2}-(\mathrm{COOH})_{2}$ for which the average $\rho$ values from the model are $71^{\circ}$ for the aromatic ring and $74^{\circ}-75^{\circ}$ for the $\mathrm{COOH} / \mathrm{COO}^{-}$. This seems to be consistent with the experimental finding that all moieties exhibit essentially the same orientation and the obvious interpretation of these averaged values is that all entities are coplanar. However, the pronouncedly different values $\left(67^{\circ}\right.$ and $\left.85^{\circ}\right)$ for the two $\mathrm{COOH}$ groups in the unit cell of the model offer a different explanation which, as seen in the model of Fig. 12, is a pronounced rotation of the $\mathrm{COOH}$ moieties out of the plane of the benzene rings, thus, enabling $\mathrm{H}$-bonding along the zig-zag chains.

\section{CONCLUSION}

The molecularly resolved microscopic and spectroscopic studies of the series of aromatic carboxylic acids presented here demonstrate that highly ordered monolayers are formed by anchoring the molecules via silver-carboxylate coordination bonding. In combination with our earlier studies on SAMs of trimesic ${ }^{37}$ and biphenyltricarboxylic acid ${ }^{38}$ the picture emerges that the Ag surface should enable a flexible design of SAM structures. Unlike carboxylic acids on $\mathrm{Cu}^{35,37-3^{8}}$ or other types of SAMs on metal surfaces like thiols or selenols ${ }^{62-63}$. 76-77 where the head group-substrate interaction plays a dominant role for the film structure, the weaker carboxylate-Ag interaction decisively shifts the balance of structure determining factors towards intermolecule interactions. This promises more flexibility in the design of SAMs as a mismatch between the molecular lattice and the substrate does not introduce stress to the extent that formation of a structurally well-defined layer is impeded. Without the dominance of the molecule-substrate 
interaction it should be more straightforward to adapt bulk derived design principles for the two-dimensional systems. With conformational flexibility adding additional degrees of freedom in the design of layers the studies also illustrate the need for calculations to assist the interpretation of the experimental data.

\section{ASSOCIATED CONTENT}

Supporting Information. Additional STM images, table compiling XPS data, description of the calculation of molecular orientation from the models and conformational energy dependencies of the biphenyl carboxylic acids. This material is available free of charge via the Internet at http://pubs.acs.org.

The research data supporting this publication can be accessed at DOI..../(to be inserted upon acceptance of manuscript).

\section{AUTHOR INFORMATION}

\section{Corresponding Author}

* Fax: +441334 4638o8; Tel: +441334 46380o; Email: mb45@standrews.ac.uk

\section{Present Addresses}

$\dagger$ Department of Chemical and Process Engineering, University of Strathclyde, James Weir Building, 75 Montrose Street, Glasgow G1 1XJ, United Kingdom

‡ Max Planck Institute for Polymer Research, Ackermannweg 10, 55128 Mainz, Germany

\section{Notes}

The authors declare no competing financial interest.

\section{ACKNOWLEDGMENT}

Support by The Leverhulme Trust (RGP-2013-177) and EPSRC via a doctoral training grant (H.A.) is gratefully acknowledged. MZ is obliged to A. Nefedov and Ch. Wöll (Karlsruhe Institute of Technology, KIT) for the technical cooperation at BESSY II and recognize the assistance of Tobias Wächter and the BESSY II staff during the synchrotron-related experiments. We also thank EaStCHEM for computational support via the EaStCHEM Research Computing Facility.

\section{ABBREVIATIONS}

DFT, density functional theory; TDM, transition dipole moment; IPA, benzene-1,3-dicarboxylic acid; TMA, 1,3,5tricarboxylic acid; Ph-COOH, benzoic acid; BPTCA, biphenyl-3,4',5-tricarboxylic acid; $\mathrm{Ph}_{2}-\mathrm{COOH}$, biphenyl-4- carboxylic acid; $\mathrm{Ph}_{3}-\mathrm{COOH}$, terphenyl-4-carboxylic acid; $\mathrm{Ph}$ $(\mathrm{COOH})_{2}$, terephthalic acid; $\mathrm{Ph}_{2}-(\mathrm{COOH})_{2}$, biphenyl-4,4'dicarboxylic acid; NEXAFS, near-edge X-ray absorption fine structure spectroscopy; STM, scanning tunneling microscopy; XPS, X-ray photoelectron spectroscopy.

\section{REFERENCES}

1. Barth, J. V. Molecular architectonic on metal surfaces. Annu. Rev. Phys. Chem. 2007, 58, 375-407.

2. Elemans, J.; Lei, S. B.; De Feyter, S. Molecular and Supramolecular Networks on Surfaces: From Two-Dimensional Crystal Engineering to Reactivity. Angew. Chem. Int. Ed. 2009, 48, 7298-7332.

3. Nath, K. G.; Ivasenko, O.; MacLeod, J. M.; Miwa, J. A.; Wuest, J. D.; Nanci, A.; Perepichka, D. F.; Rosei, F. Crystal Engineering in Two Dimensions: An Approach to Molecular Nanopatterning. J. Phys. Chem. C 2007, 111, 16996-17007.

4. Slater, A. G.; Beton, P. H.; Champness, N. R. Two-dimensional supramolecular chemistry on surfaces. Chem. Sci. 2011, 2, 14401448 .

5. Lackinger, M. Self-Healing in Two-Dimensional Supramolecular Structures Utilizing Thermodynamic Driving Forces. In Self-Healing at the Nanoscale, Amendola, V.; Meneghetti, M., Eds.; Taylor and Francis, 2012, p 467.

6. Canas-Ventura, M. E.; Klappenberger, F.; Clair, S.; Pons, S.; Kern, K.; Brune, H.; Strunskus, T.; Wöll, C.; Fasel, R.; Barth, J. V. Coexistence of one- and two-dimensional supramolecular assemblies of terephthalic acid on $\operatorname{Pd}(111)$ due to self-limiting deprotonation. $J$. Chem. Phys. 2006, 125, 1-8.

7. Suzuki, T.; Lutz, T.; Payer, D.; Lin, N.; Tait, S. L.; Costantini, G.; Kern, K. Substrate effect on supramolecular self-assembly: from semiconductors to metals. Phys. Chem. Chem. Phys. 2009, 11, 64986504.

8. Blunt, M. O.; Russell, J. C.; Gimenez-Lopez, M. D.; Garrahan, J. P.; Lin, X.; Schroder, M.; Champness, N. R.; Beton, P. H. Random Tiling and Topological Defects in a Two-Dimensional Molecular Network. Science 2008, 322, 1077-1081.

9. MacLeod, J. M.; Ben Chaouch, Z.; Perepichka, D. F.; Rosei, F. TwoDimensional Self-Assembly of a Symmetry-Reduced Tricarboxylic Acid. Langmuir 2013, 29, 7318-7324.

10. Payer, D.; Comisso, A.; Dmitriev, A.; Strunskus, T.; Lin, N.; Wöll, C.; DeVita, A.; Barth, J. V.; Kern, K. Ionic hydrogen bonds controlling two-dimensional supramolecular systems at a metal surface. Chem. Eur. J. 2007, 13, 3900-3906.

11. Florio, G. M.; Stiso, K. A.; Campanelli, J. S. Surface Patterning of Benzenecarboxylic Acids: Influence of Structure, Solvent, and Concentration on Molecular Self-Assembly. J. Phys. Chem. C 2012, 116, 18160-18174.

12. Addou, R.; Batzill, M. Defects and Domain Boundaries in SelfAssembled Terephthalic Acid (TPA) Monolayers on CVD-Grown Graphene on $\operatorname{Pt}(111)$. Langmuir 2013, 29, 6354-6360.

13. Kim, Y.-G.; Yau, S.-L.; Itaya, K. In Situ Scanning Tunneling Microscopy of Highly Ordered Adlayers of Aromatic Molecules on Well-Defined Pt(111) Electrodes in Solution: Benzoic Acid, Terephthalic Acid, and Pyrazine. Langmuir 1999, 15, 7810-7815.

14. Zelenay, P.; Waszczuk, P.; Dobrowolska, K.; Sobkowski, J. ADSORPTION OF BENZOIC-ACID ON A POLYCRYSTALLINE GOLD ELECTRODE. Electrochim. Acta 1994, 39, 655-660.

15. Ishikawa, Y.; Ohira, A.; Sakata, M.; Hirayama, C.; Kunitake, M. A two-dimensional molecular network structure of trimesic acid prepared by adsorption-induced self-organization. Chem. Commun. 2002, 2652-2653.

16. Su, G. J.; Zhang, H. M.; Wan, L. J.; Bai, C. L.; Wandlowski, T. Potential-induced phase transition of trimesic acid adlayer on Au(111). J. Phys. Chem. B 2004, 108, 1931-1937.

17. Ikezawa, Y.; Masuda, R. Adsorption behavior of terephthalic acid on $\mathrm{Au}(100), \mathrm{Au}(111)$ and $\mathrm{Au}(110)$ electrodes in neutral solution. Electrochim. Acta 2008, 53, 5456-5463. 
18. Haensch, C.; Hoeppener, S.; Schubert, U. S. Chemical modification of self-assembled silane based monolayers by surface reactions. Chem. Soc. Rev. 2010, 39, 2323-2334.

19. Claridge, S. A.; Liao, W.-S.; Thomas, J. C.; Zhao, Y.; Cao, H. H.; Cheunkar, S.; Serino, A. C.; Andrews, A. M.; Weiss, P. S. From the bottom up: dimensional control and characterization in molecular monolayers. Chem. Soc. Rev. 2013, 42, 2725-2745.

20. Martin, D. S.; Cole, R. J.; Haq, S. Creating a functionalized surface: The adsorption of terephthalic acid onto $\mathrm{Cu}(110)$. Phys. Rev. B 2002, $66,1-8$

21. Dmitriev, A.; Lin, N.; Weckesser, J.; Barth, J. V.; Kern, K. Supramolecular assemblies of trimesic acid on a $\mathrm{Cu}(100)$ surface. $J$. Phys. Chem. B 2002, 106, 6907-6912.

22. Frederick, B. G.; Chen, Q.; Leibsle, F. M.; Lee, M. B.; Kitching, K. J.; Richardson, N. V. Long-range periodicity in $\mathrm{c}(8 \times 2)$ benzoate/Cu(110): a combined STM, LEED and HREELS study. Surf. Sci. 1997, 394, 1-25.

23. Chen, Q.; Perry, C. C.; Frederick, B. G.; Murray, P. W.; Haq, S.; Richardson, N. V. Structural aspects of the low-temperature deprotonation of benzoic acid on $\mathrm{Cu}(110)$ surfaces. Surf. Sci. 2000, 446, 63-75

24. Dmitriev, A.; Spillmann, H.; Stepanow, S.; Strunskus, T.; Wöll, C.; Seitsonen, A. P.; Lingenfelder, M.; Lin, N.; Barth, J. V.; Kern, K. Asymmetry induction by cooperative intermolecular hydrogen bonds in surface-anchored layers of achiral molecules. ChemPhysChem 2006, 7, 2197-2204.

25. Tekiel, A.; Prauzner-Bechcicki, J. S.; Godlewski, S.; Budzioch, J.; Szymonski, M. Self-assembly of terephthalic acid on rutile TiO2(110): Toward chemically functionalized metal oxide surfaces. $J$. Phys. Chem. C 2008, 112, 12606-12609.

26. Rahe, P.; Nimmrich, M.; Nefedov, A.; Naboka, M.; Wöll, C.; Kühnle, A. Transition of Molecule Orientation during Adsorption of Terephthalic Acid on Rutile TiO2(110). J. Phys. Chem. C 2009, 113, 17471-17478.

27. Tait, S. L.; Lim, H.; Theertham, A.; Seidelz, P. First layer compression and transition to standing second layer of terephthalic acid on Cu(100). Phys. Chem. Chem. Phys. 2012, 14, 8217-8223.

28. Ge, Y.; Adler, H.; Theertham, A.; Kesmodel, L. L.; Tait, S. L. Adsorption and Bonding of First Layer and Bilayer Terephthalic Acid on the $\mathrm{Cu}(100)$ Surface by High-Resolution Electron Energy Loss Spectroscopy. Langmuir 2010, 26, 16325-16329.

29. Ulman, A. Formation and structure of self-assembled monolayers. Chem. Rev. 1996, 96, 1533-1554.

30. Jadhav, S. A. Self-assembled monolayers (SAMs) of carboxylic acids: an overview. Central European Journal of Chemistry 2011, 9, 369378.

31. Platzman, I.; Saguy, C.; Brener, R.; Tannenbaum, R.; Haick, H. Formation of Ultrasmooth and Highly Stable Copper Surfaces through Annealing and Self-Assembly of Organic Monolayers. Langmuir 2010, 26, 191-201.

32. Hsu, M. H.; Hu, W. S.; Lin, J. J.; Hsu, Y. J.; Wei, D. H.; Yang, C. W.; Chang, C. S.; Tao, Y. T. H2S-induced reorganization of mixed monolayer of carboxylic derivatives on silver surface. Langmuir 2004, 20, 3641-3647.

33. Tao, Y. T.; Lee, M. T.; Chang, S. C. Effect of Biphenyl and Naphthyl Groups on the Structure of Self-Assembled Monolayers - Packing, Orientation, and Wetting Properties J. Am. Chem. Soc. 1993, 115, 9547-9555.

34. Tao, Y.-T.; Lin, W.-L.; Hietpas, G. D.; Allara, D. L. Infrared Spectroscopic Study of Chemically Induced Dewetting in Liquid Crystalline Types of Self-Assembled Monolayers. J. Phys. Chem. B 1997, 101, 9732-9740.

35. Cebula, I.; Shen, C.; Buck, M. Isophthalic Acid: A Basis for Highly Ordered Monolayers. Angew. Chem. Int. Ed. 2010, 49, 6220-6223.

36. Shen, C.; Cebula, I.; Brown, C.; Zhao, J.; Zharnikov, M.; Buck, M. Structure of isophthalic acid based monolayers and its relation to the initial stages of growth of metal-organic coordination layers. Chem. Sci. 2012, 3, 1858-1865.

37. Cebula, I.; Lu, H.; Zharnikov, M.; Buck, M. Monolayers of trimesic and isophthalic acid on $\mathrm{Cu}$ and $\mathrm{Ag}$ : the influence of coordination strength on adsorption geometry. Chem. Sci. 2013, 4, 4455-4464.
38. Aitchison, H.; Lu, H.; Zharnikov, M.; Buck, M. Monolayers of Biphenyl-3,4',5-tricarboxylic Acid Formed on $\mathrm{Cu}$ and $\mathrm{Ag}$ from Solution. J. Phys. Chem. C 2015, 119, 14114-14125.

39. Herrero, E.; Buller, L. J.; Abruña, H. D. Underpotential Deposition at Single Crystal Surfaces of $\mathrm{Au}, \mathrm{Pt}, \mathrm{Ag}$ and Other Materials. Chem. Rev. 2001, 101, 1897-1930.

40. Kondo, T.; Takakusagi, S.; Uosaki, K. Stability of underpotentially deposited Ag layers on a $\mathrm{Au}(111)$ surface studied by surface X-ray scattering. Electrochem. Commun. 2009, 11, 804-807.

41. Baker, M. V.; Jennings, G. K.; Laibinis, P. E. Underpotentially deposited copper promotes self-assembly of alkanephosphonate monolayers on gold substrates. Langmuir 2000, 16, 3288-3293.

42. Lin, S. Y.; Tsai, T. K.; Lin, C. M.; Chen, C. H.; Chan, Y. C.; Chen, H. W. Structures of self-assembled monolayers of n-alkanoic acids on gold surfaces modified by underpotential deposition of silver and copper: Odd-even effect. Langmuir 2002, 18, 5473-5478.

43. Chen, C. H.; Vesecky, S. M.; Gewirth, A. A. In Situ Atomic Force Microsopy of Underpotential Deposition of Ag on Au(111) J. Am. Chem. Soc. 1992, 114, 451-458.

44. Garcia, S.; Salinas, D.; Mayer, C.; Schmidt, E.; Staikov, G.; Lorenz W. J. Ag UPD on Au(100) and Au(111). Electrochim. Acta 1998, 43, 3007-3019.

45. Esplandiu, M. J.; Schneeweiss, M. A.; Kolb, D. M. An in situ scanning tunneling microscopy study of Ag electrodeposition on Au(111). Phys. Chem. Chem. Phys. 1999, 1, 4847-4854.

46. Moulder, J. F.; Chastain, J. Handbook of X-Ray Photoelectron Spectroscopy: A Reference Book of Standard Spectra for Identification and Interpretation of XPS Data; Perkin-Elmer Corporatioon, Physical Electronics Division1992.

47. Stöhr, J. NEXAFS Spectroscopy; Springer1992.

48. Batson, P. E. Carbon 1s near-edge-absorption fine structure in graphite. Phys. Rev. B 1993, 48, 2608-2610.

49. Kresse, G.; Hafner, J. Ab Initio Molecular-Dynamics for LiquidMetals. Phys. Rev. B 1993, 47, 558-561.

50. Kresse, G.; Hafner, J. Ab-Initio Molecular-Dynamics Simulation of the Liquid-Metal Amorphous-Semiconductor Transition in Germanium. Phys. Rev. B 1994, 49, 14251-14269.

51. Kresse, G.; Furthmüller, J. Efficiency of ab-initio total energy calculations for metals and semiconductors using a plane-wave basis set. Comp. Mat. Sci. 1996, 6, 15-50.

52. Perdew, J. P.; Burke, K.; Ernzerhof, M. Generalized gradient approximation made simple. Phys. Rev. Lett. 1996, 77, 3865-3868.

53. Perdew, J. P.; Burke, K.; Ernzerhof, M. Generalized gradient approximation made simple (vol 77, pg 3865, 1996). Phys. Rev. Lett. 1997, 78, 1396-1396.

54. Grimme, S. Semiempirical GGA-type density functional constructed with a long-range dispersion correction. J. Comput. Chem. 2006, 27, 1787-1799.

55. Makov, G.; Payne, M. C. Periodic Boundary-Conditions in ab-initio Calculations Phys. Rev. B 1995, 51, 4014-4022.

56. Neugebauer, J.; Scheffler, M. Adsorbate-Substrate and AdsorbateAdsorbate Interactions of $\mathrm{Na}$ and $\mathrm{K}$ Adlayers on $\mathrm{Al}(111)$. Phys. Rev. $B$ 1992, 46, 16067-16080.

57. Cyganik, P.; Buck, M.; Wilton-Ely, J. D. E. T.; Wöll, C. Stress in Self-Assembled Monolayers: The Case of $\omega$-Biphenyl-Alkane Thiols on Au(111). J. Phys. Chem. B 2005, 109, 10902-10908.

58. Azzam, W.; Fuxen, C.; Birkner, A.; Rong, H. T.; Buck, M.; Wöll, C. Coexistence of different structural phases in thioaromatic monolayers on $\mathrm{Au}(111)$. Langmuir 2003, 19, 4958-4968.

59. Sinnokrot, M. O.; Valeev, E. F.; Sherrill, C. D. Estimates of the ab initio limit for pi-pi interactions: The benzene dimer. J. Am. Chem. Soc. 2002, 124, 10887-10893.

60. Prauzner-Bechcicki, J. S.; Godlewski, S.; Tekiel, A.; Cyganik, P.; Budzioch, J.; Szymonski, M. High-Resolution STM Studies of Terephthalic Acid Molecules on Rutile $\mathrm{TiO}_{2}(110)-(1$ x 1) Surfaces. $J$. Phys. Chem. C 2009, 113, 9309-9315.

61. Zasada, F.; Piskorz, W.; Godlewski, S.; Prauzner-Bechcicki, J. S.; Tekiel, A.; Budzioch, J.; Cyganik, P.; Szymonski, M.; Sojka, Z. Chemical Functionalization of the $\mathrm{TiO}_{2}(110)-(1 \mathrm{x}$ 1) Surface by Deposition of Terephthalic Acid Molecules. A Density Functional Theory and Scanning Tunneling Microscopy Study. J. Phys. Chem. C 2011, 115, 4134-4144. 
62. Cyganik, P.; Buck, M.; Strunskus, T.; Shaporenko, A.; Wilton-Ely, J. D. E. T.; Zharnikov, M.; Wöll, C. Competition as a design concept: Polymorphism in self-assembled monolayers of biphenyl-based thiols. J. Am. Chem. Soc. 2006, 128, 13868-13878.

63. Dendzik, M.; Terfort, A.; Cyganik, P. Odd-Even Effect in the Polymorphism of Self-Assembled Mono layers of BiphenylSubstituted Alkaneselenolates on Au(111). J. Phys. Chem. C 2012, 116, 19535-19542.

64. Cyganik, P.; Buck, M.; Azzam, W.; Wöll, C. Self-Assembled Monolayers of $\omega$-Biphenyl-Alkane Thiols on $\mathrm{Au}(111)$ : Influence of Spacer Chain on Molecular Packing. J. Phys. Chem. B 2004, 108, 4989-4996.

65. Lin, N.; Payer, D.; Dmitriev, A.; Strunskus, T.; Wöll, C.; Barth, J. V.; Kern, K. Two-dimensional adatom gas bestowing dynamic heterogeneity on surfaces. Angew. Chem. Int. Ed. 2005, 44, 14881491.

66. Classen, T.; Lingenfelder, M.; Wang, Y.; Chopra, R.; Virojanadara, C.; Starke, U.; Costantini, G.; Fratesi, G.; Fabris, S.; de Gironcoli, S.; Baroni, S.; Haq, S.; Raval, R.; Kern, K. Hydrogen and coordination bonding supramolecular structures of trimesic acid on $\mathrm{Cu}(110) . J$. Phys. Chem. A 2007, 111, 12589-12603.

67. Shaporenko, A.; Terfort, A.; Grunze, M.; Zharnikov, M. A detailed analysis of the photoemission spectra of basic thioaromatic monolayers on noble metal substrates. J. Electron. Spectrosc. Relat. Phenom. 2006, 151, 45-51.

68. Stepanow, S.; Strunskus, T.; Lingenfelder, M.; Dmitriev, A.; Spillmann, H.; Lin, N.; Barth, J. V.; Wöll, C.; Kern, K. Deprotonation-driven phase transformations in terephthalic acid selfassembly on $\mathrm{Cu}(100)$. J. Phys. Chem. B 2004, 108, 19392-19397.

69. Okajima, T.; Teramoto, K.; Mitsumoto, R.; Oji, H.; Yamamoto, Y.; Mori, I.; Ishii, H.; Ouchi, Y.; Seki, K. Polarized NEXAFS spectroscopic studies of poly(butylene terephthalate), poly(ethylene terephthalate), and their model compounds. J. Phys. Chem. A 1998, 102, 7093-7099.
70. Rodriguez-Cuamatzi, P.; Arillo-Flores, O. I.; Bernal-Urucurtu, M. I.; Hoepfl, H. Experimental and theoretical analysis of the hydrogenbonding motifs formed between the carboxyl and the carboxylate classification of group: Towards a systematic their supramolecular motifs. Supramol. Chem. 2007, 19, 559-578.

71. Kreikemeyer-Lorenzo, D.; Unterberger, W.; Duncan, D. A.; Bradley, M. K.; Lerotholi, T. J.; Robinson, J.; Woodruff, D. P. Face-Dependent Bond Lengths in Molecular Chemisorption: The Formate Species on $\mathrm{Cu}(111)$ and $\mathrm{Cu}(110)$. Phys. Rev. Lett. 2011, 107, 046102.

72. Steiner, T. The hydrogen bond in the solid state. Angew. Chem. Int. Ed. 2002, 41, 48-76.

73. Takusagawa, F.; Hirotsu, K.; Shimada, A. The Crystal Structure of Trimellitic Acid for the Pseudo-cell. Bull. Chem. Soc. Jpn. 1973, 46, 2960-2965.

74. Ballav, N.; Schüpbach, B.; Dethloff, O.; Feulner, P.; Terfort, A.; Zharnikov, M. Direct Probing Molecular Twist and Tilt in Aromatic Self-Assembled Monolayers. J. Am. Chem. Soc. 2007, 129, 1541615417.

75. Liu, J. X.; Schüpbach, B.; Bashir, A.; Shekhah, O.; Nefedov, A.; Kind, M.; Terfort, A.; Wöll, C. Structural characterization of selfassembled monolayers of pyridine-terminated thiolates on gold. Phys. Chem. Chem. Phys. 2010, 12, 4459-4472.

76. Schreiber, F. Structure and growth of self-assembling monolayers. Prog. Surf. Sci. 2000, 65, 151-256.

77. Gnatek, D.; Schuster, S.; Ossowski, J.; Khan, M.; Rysz, J.; Krakert, S.; Terfort, A.; Zharnikov, M.; Cyganik, P. Odd-Even Effects in the Structure and Stability of Azobenzene-Substituted Alkanethiolates on $\mathrm{Au}(111)$ and $\mathrm{Ag}(111)$ Substrates. J. Phys. Chem. C 2015, 119, 2592925944. 

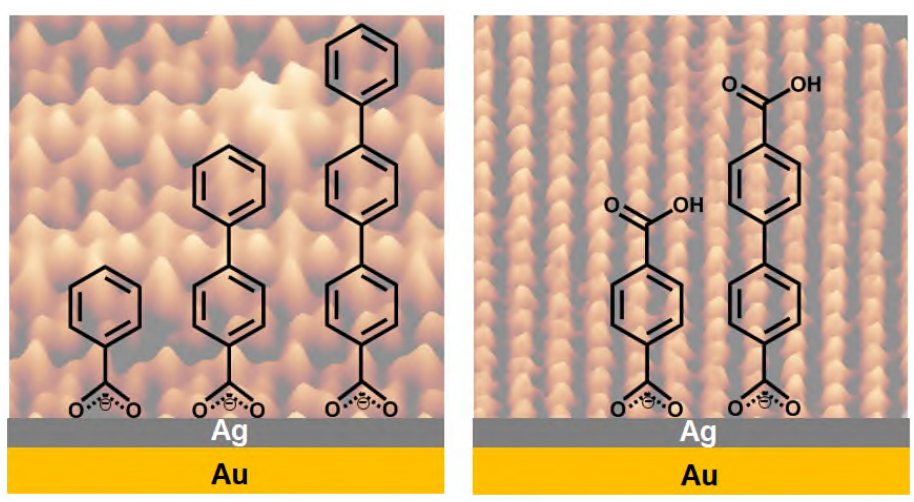